\title{
Tunnel-framed building interaction: comparison between raft and separate footing foundations
}

\author{
JINGMIN XU*, A. FRANZA $\dagger$, A. M. MARSHALL** N. LOSACCO $\ddagger$, and D. BOLDINI§
}

\begin{abstract}
This paper investigates the influence of the foundation configuration (raft or separate footings) on tunnel-soil-framed building interaction using geotechnical centrifuge testing. Tunnelling-induced soil movements and deformation fields, framed building displacements, and structure shear distortions (with associated modification factors) are illustrated. Framed building stiffness and footing bearing capacity are also evaluated experimentally. Results show that the foundation configuration plays an important role in determining the ground response to tunnelling, affecting soil displacement fields as well as the distribution of soil shear and volumetric strains. In particular, foundation settlements and differential horizontal displacements are larger for separate footings compared to raft foundations. The effects of building width, weight, and eccentricity (with respect to the tunnel) on foundation settlements and structural distortions is quantified for separate footings and contrasted against results for raft foundations. The modification factor of the maximum building shear distortion is linked to the relative soil-building shear stiffness; interestingly, for buildings with similar values of relative stiffness, the level of shear distortion within framed buildings is lower for separate footings than rafts.
\end{abstract}

KEYWORDS: Tunnels \& tunnelling, foundation configuration, soil/structure interaction, frame, centrifuge modelling

\section{INTRODUCTION}

New tunnels are frequently excavated during the development and expansion of urban areas. To minimise the potential risk of tunnelling-induced ground movements on existing structures, it is important to be able to efficiently predict building distortions considering soil-structure interaction.

Although the structural characteristics of framed buildings need to be considered in tunnel-soil-structure modelling (Boldini et al., 2018; Elkayam \& Klar, 2019; Fu et al., 2018; Franza \& DeJong, 2019; Comodromos et al., 2014) and risk assessments (Boone, 1996), equivalent beam or plate models with minimal shear flexibility are still often adopted (Franzius et al., 2006; Haji et al., 2018). However, Xu et al. (2020) recently provided experimental evidence that framed buildings on raft foundations primarily exhibit shear distortions when subjected to tunnelling-induced displacements and suggested, by contrasting framed building results with equivalent plate test results from Farrell et al. (2014), that the use of equivalent beams/plates with minimal shear flexibility may not be adequate for framed buildings.

With regard to foundation effects, while structural horizontal strains at the ground level are negligible for continuous foundations (Franzius et al., 2006; Dimmock \& Mair, 2008), discontinuous foundations can result in large differential horizontal displacements (Laefer et al., 2009; Goh \& Mair, 2014; Fu et al., 2018), which have the potential to affect the deformation mechanisms of framed buildings (Franza \& DeJong, 2019; Fu et al., 2018). Experimental data related to tunnelling-induced ground displacements and deformations are limited to continuous foundations (i.e. strips and rafts) (Farrell et al., 2014; Ritter et al., 2017), whereas field data are sparse with limited insights into the subsurface soil behaviour (Dimmock \& Mair, 2008; Goh \& Mair, 2014). Because of the lack of a systematic experimental investigation of the effects of foundation configuration on both structural distortion and soil movements, the research community is limited in their capability to develop and verify reliable numerical and analytical tools.

\footnotetext{
Manuscript received...

* Department of Civil Engineering, University of Nottingham, Nottingham, UK.

$\dagger$ ETSI Caminos, Canales y Puertos, Technical University of Madrid, Madrid, Spain.

$\ddagger$ Department of Civil, Environmental, Land, Building Engineering and Chemistry, Polytechnic University of Bari, Bari, Italy.

$\S$ Department of Chemical Engineering Materials Environment, Sapienza University of Rome, Rome, Italy
} 
SCOPE

This paper investigates the influence of foundation configuration on the tunnel-soil-frame interaction. Here, two configurations are considered: a 'raft' foundation that is continuous beneath the entire building footprint, and a 'separate footing' foundation (strip footings parallel to the tunnel axis) that is discontinuous in the direction transverse to the tunnel axis (see Figure 1). The paper presents data obtained from plane-strain geotechnical centrifuge tests using dry sand: novel experiments including 10 tests simulating tunnelling beneath frames on separate footings and 3 tests characterising the individual footing bearing capacity; and published data from 2 greenfield tunnelling tests and 10 tests of tunnelling beneath frames on raft foundations from Xu et al. (2020). Greenfield and raft foundation test data are used here as a reference for comparison with the separate footing results. A parametric study considering building width, weight, eccentricity (i.e. lateral offset from the location of the tunnel), and soil density is presented.

\section{CENTRIFUGE EXPERIMENTAL DETAILS}

Tests were performed on the University of Nottingham Centre for Geomechanics $4 \mathrm{~m}$ diameter geotechnical centrifuge. The plane-strain experimental package developed by Zhou et al. (2014) was used, including a strongbox, a transparent acrylic front wall to allow acquisition of digital images of the subsurface, an aluminium back wall, a flexible membrane model tunnel (diameter $D_{t}=90 \mathrm{~mm}$ ) filled with water, and a tunnel volume loss control system. A fine-grained dry silica sand (Leighton Buzzard Fraction E), with minimum and maximum voids ratios of 0.65 and 1.01 was used (characterised by Zhao (2008) and Lanzano et al. (2016)).

In the experiments, the construction of a tunnel beneath a framed building with either a raft foundation or separate footings was simulated. Two model building widths were considered: a long building with width $B_{l}=462 \mathrm{~mm}$ and a short building with $B_{s}=232 \mathrm{~mm}$. The model tunnel had a cover, $C$, of $117 \mathrm{~mm}\left(C / D_{t}=1.3\right)$ in all tests. Figure 1 shows the tunnel and building parameters in model scale. In particular, the width of the footing $\left(b_{\text {foot }}\right)$ is $12 \mathrm{~mm}$ and the height of the footing column equals that of the storey height $h_{\text {storey }}(38.1 \mathrm{~mm})$. Building elements in all models are $3.2 \mathrm{~mm}$ thick, and the bay width $b_{b a y}$ of the model frame in the direction transverse to the tunnel is $76.2 \mathrm{~mm}$. To achieve plane-strain conditions, all the building elements spanned the full extent $(258 \mathrm{~mm})$ of the framed building model in the tunnel longitudinal direction, leaving a $1 \mathrm{~mm}$ gap between the building model and front/back walls of the $260 \mathrm{~mm}$ wide centrifuge strongbox.
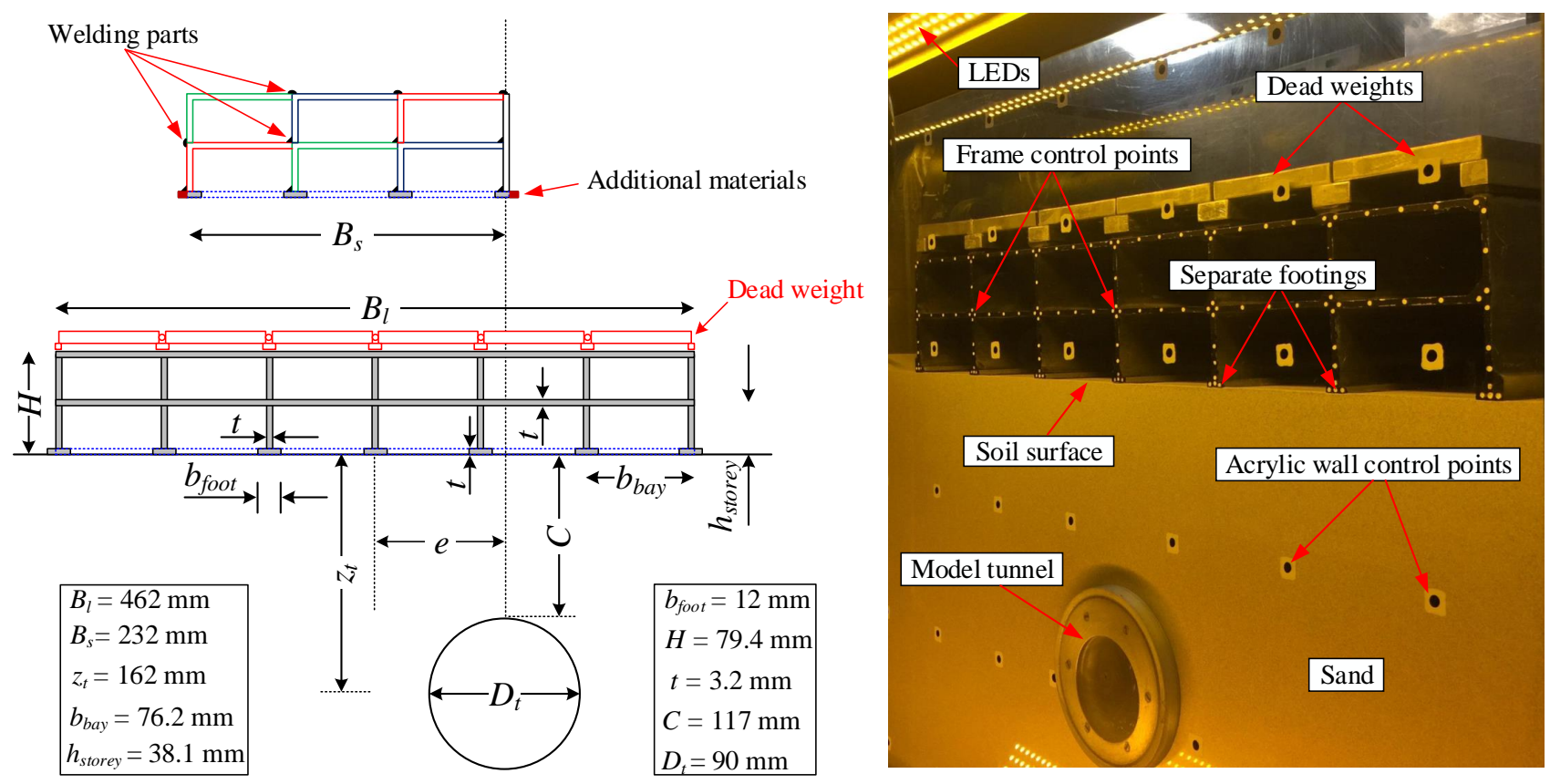

Fig. 1. Experimental set-up: (left) test layout in model scale dimensions, (right) view of the model.

The bare framed building models were manufactured by machining and welding two aluminium plates (one as the foundation plate and one side wall) and several angles, as illustrated in Figure 1 for the short frame model. Note that infill-walls were not physically modelled. For the connection between walls and slabs, $60 \%$ of the length (along the tunnel axis direction) was welded (Xu et al., 2019). The frames with separate footings were made from the raft foundation models by machining out the aluminium plate at the base of the model (dotted lines in Figure 1); epoxy was added to the external footings to achieve the desired footing width of $12 \mathrm{~mm}$. 
To replicate a rough soil foundation interface, a thin layer of sand was bonded to the underside of the building foundations. The GeoPIV digital image analysis technique (White et al., 2003) was used to measure both soil and structure displacements during tests. Structure displacements were obtained by tracking white dots painted on the front face of the building models (matt black background was painted prior to the white dots). A Dalsa Genie Nano-M4020 monochrome camera (with a 12.4-megapixel sensor and 8mm Tamron lens) and single wavelength light-emitting diodes were used (Xu et al., 2020).

The tests were conducted at an elevated gravity level of $68 \mathrm{~g}$, representing a prototype scenario with a $D_{t}=6.1 \mathrm{~m}$ diameter tunnel beneath either a $31.4 \mathrm{~m}$ or a $15.8 \mathrm{~m}$ wide building. The structural element thickness of the prototype buildings is $0.22 \mathrm{~m}$, the bay width is $5.2 \mathrm{~m}$, and inter-storey height is $2.6 \mathrm{~m}$. Considering that aluminium and concrete have a similar Young's modulus (which is not affected by the centrifuge scaling laws), the prototype cross-sectional stiffness of slabs and walls realistically replicates typical reinforced concrete structures.

Data from 25 centrifuge tests are presented in this paper, as shown in Table 1 and Figure 2: 2 greenfield tests, 20 tunnel-frame interaction tests, and 3 loading tests for isolated footings. For a given frame model, the relative density of the sand $\left(I_{d}=30,90 \%\right)$, the eccentricity $(e)$ of the model building with respect to the tunnel, and the building self-weight (SW: standard self-weight; 2SW: double self-weight) were varied in the experiments. The standard self-weight SW is due to the weight of the aluminium used for the frame models (calculated for in-flight conditions considering the variation of gravity level across the height of the models). The double self-weight $2 \mathrm{SW}$ was achieved by adding simply supported (at wall locations) weights to the top of the frames; this system ensured that the additional weight did not increase the frame stiffness (see Figure 1). For the long frame, a total of 4 tests were performed for each foundation configuration: 2 tests involving a central tunnel in loose and dense soil for a standard weight SW building, 1 test with a central tunnel in dense sand and the 2SW frame, and 1 test for an eccentric tunnel case with $e / B=0.2$ in loose sand and the SW frame. For the short building model, 6 tests were performed for each foundation configuration: for the loose sand, normalised eccentricity $e / B$ of 0 and 0.5 was tested for the standard weight SW case only; for dense sand, both cases of $e / B(0$ and 0.5$)$ and building weight (SW and $2 \mathrm{SW}$ ) were tested.

Table 1. Centrifuge testing plan.

\begin{tabular}{|c|c|c|c|c|c|}
\hline Total No. & Label & Foundation type & $I_{d}(\%)$ & $e / B$ & Weight (pressure ${ }^{\dagger}, \mathrm{kPa}$ ) \\
\hline 2 & Greenfield $^{*}$ & - & $30 \& 90$ & - & - \\
\hline \multirow{2}{*}{6} & \multirow{2}{*}{ Short } & \multirow{2}{*}{ Raft* } & 30 & $0 \& 0.5$ & SW(19.4) \\
\hline & & & 90 & $0 \& 0.5$ & SW(19.4) \& 2SW(38.8) \\
\hline \multirow{2}{*}{6} & \multirow{2}{*}{ Short } & \multirow{2}{*}{ Separate footings } & 30 & $0 \& 0.5$ & $\mathrm{SW}(94.4)$ \\
\hline & & & 90 & $0 \& 0.5$ & SW(94.4) \& 2SW(189) \\
\hline \multirow{2}{*}{4} & \multirow{2}{*}{ Long } & \multirow{2}{*}{ Raft $^{*}$} & 30 & $0 \& 0.2$ & SW $(22.8)$ \\
\hline & & & 90 & 0 & $\mathrm{SW}(22.8) \& 2 \mathrm{SW}(45.6)$ \\
\hline \multirow{2}{*}{4} & \multirow{2}{*}{ Long } & \multirow{2}{*}{ Separate footings } & 30 & $0 \& 0.2$ & SW $(103)$ \\
\hline & & & 90 & 0 & SW(103) \& 2SW(206) \\
\hline 3 & Loading & Separate footings & $30 \& 90$ & - & - \\
\hline
\end{tabular}

$\dagger$ Average value beneath the foundation at $68 \mathrm{~g}$

* Data from Xu et al. (2020)
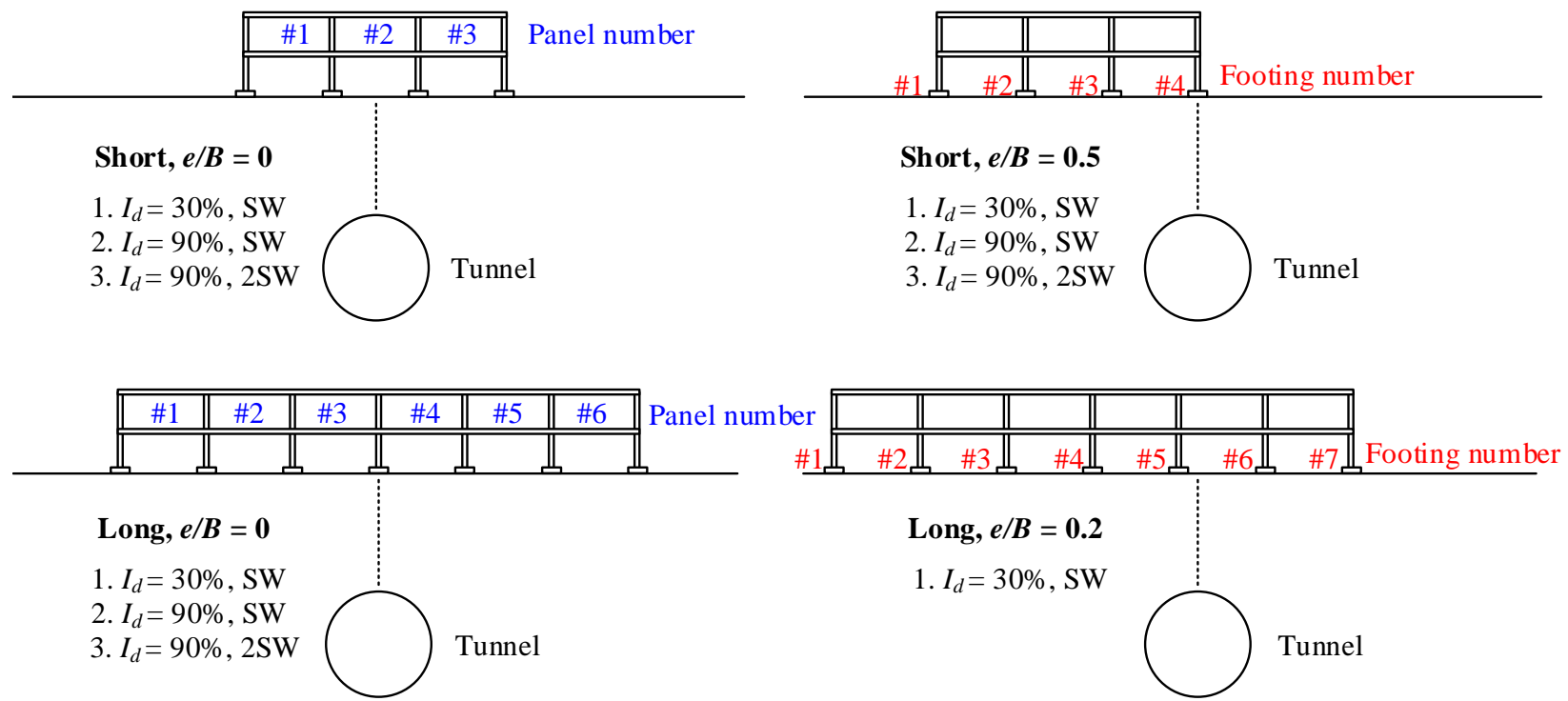

Fig. 2. Illustration of the centrifuge testing plan. 
The preparation of the centrifuge models for dense $\left(I_{d}=90 \%\right)$ and loose $\left(I_{d}=30 \%\right)$ sand tests was different. The dense sand was poured into the container in-line with the model tunnel (consistent with Marshall et al. (2012); Farrell et al. (2014); Franza et al. (2019)) before moving the package onto the centrifuge cradle. The preparation of loose sand models was carried out with the experimental package on the centrifuge cradle (consistent with Xu et al. (2020); Franza \& Marshall (2018)). After pouring the loose soil sample, the surface was levelled to ensure uniform contact at the soil-foundation interface. In the tunnel-frame interaction tests, the framed building model was carefully placed on the soil surface at $1 \mathrm{~g}$, the model was then spun to $68 \mathrm{~g}$, and two stabilisation cycles were carried out (going from $68 \mathrm{~g}$ to $15 \mathrm{~g}$ and back to $68 \mathrm{~g}$ ); the stabilisation cycles are done to help obtain consistency between tests by reducing localised high-stress zones ('hung-up' particles), thereby achieving more uniformly stressed soil profiles. Tunnel volume loss $V_{l, t}$ was then simulated by extracting water from the model tunnel in increments of $0.1 \%$, aiming to obtain a uniform displacement along the tunnel axis and achieve the intended plain strain boundary condition. At each increment of $V_{l, t}$, digital images of both the soil and the structure were taken.

The loading tests were conducted to evaluate the ultimate capacity of the footings; this information is used in the interpretation of results presented later and may be useful for others conducting numerical analysis of the problem. The loading tests were performed at two locations within the strongbox: position 1 at the centre of the strongbox, and position 2 at $225 \mathrm{~mm}$ from the centre and $95 \mathrm{~mm}$ away from the side wall. These locations correspond to the positions of the central and external footings, respectively, of the long frame with $e / B=0$. Using a load controlled system, two loading conditions were implemented during the spin-up phase of the loading tests to achieve either a footing initially detached from the surface (null initial pressure $q_{0}$ ) or a footing loaded such that the average applied pressure was equivalent to the pressure beneath the model building footings (which varied during centrifuge spin-up; see Table 1 for pressures at $68 \mathrm{~g}$ ). Upon reaching $68 \mathrm{~g}$, a displacement controlled system was activated and the footing in position 1 was jacked at $0.02 \mathrm{~mm} / \mathrm{s}$ and then unloaded. The footing in position 2 was then tested in the same way.

Finally, the implications of the 2D plane-strain conditions on the foundation schemes are discussed. While the 2D 'raft' foundation is representative of rafts or continuous strips oriented transverse to the tunnel axis, the 2D 'separate footing' foundation scheme applied here is an approximation of strips placed longitudinally in the direction of the tunnel axis or discrete pads. The adoption of the $2 \mathrm{D}$ condition does, of course, imply simplifications and approximations compared to more realistic 3D tunnelling scenarios, hence results presented here should be interpreted with this in mind.

\section{OVERVIEW OF DEFORMATION PARAMETERS}

Underground excavation-induced ground movements cause building shear distortions, the assessment of which is possible by several approaches (Cook, 1994; Mair et al., 1996; Boone, 1996; Finno et al., 2005; Elkayam \& Klar, 2019). To quantify the shearing of a panel (geometrical area delimited by two columns and two slabs, as shown in Figure 3 ), it is possible to use the angular distortion $\beta$, which Son \& Cording (2005) calculated by subtracting tilt $\theta$ from the slope $s$.

$$
\beta=s-\theta=\frac{\Delta u_{t o t}}{b_{b a y}}-\left(\frac{\phi_{2}}{2}+\frac{\phi_{1}}{2}\right)
$$

where $\Delta u_{t o t}=U_{z, D}-U_{z, C} \quad$ is the total differential settlement; $\phi_{1}=\left(U_{x, C}-U_{x, A}\right) /\left(h_{\text {storey }}\right) \quad$ and $\quad \phi_{2}=$ $\left(U_{x, D}-U_{x, B}\right) /\left(h_{\text {storey }}\right)$ are left and right edge tilt, respectively; for $U_{i, j}, i=x ; z$ is the displacement direction, and $j=A ; B ; C ; D$ is the location of the panel corner. In this paper, only the shear distortions of panels confined by two columns and two slabs are considered. The lower panels for the footing foundation are not analysed because of uncertainties relating to footing differential horizontal displacements, as discussed later.

Alternatively, Cook (1994) proposed an approach to isolate tilt $\left(\Delta u_{\text {tilt }}\right)$, bending $\left(\Delta u_{\text {bend }}\right)$, and shear $\left(\Delta u_{\text {shear }}\right)$ displacements from the total differential settlement $\Delta u_{\text {tot }}$. Based on this approach, Ritter et al. (2020) derived the shear distortion $\gamma$ in Equation (2) using top and bottom corner displacements of the bay of interest (see Figure 3). Interestingly, shear distortion $\gamma$ of the structure is equal to the angular distortion $\beta$ estimated by Son \& Cording (2005).

$$
\gamma=\frac{\Delta u_{\text {shear }}}{b_{\text {bay }}}=\frac{\Delta u_{\text {tot }}}{b_{\text {bay }}}-\frac{\Delta u_{\text {tilt }}}{b_{\text {bay }}}-\frac{\Delta u_{\text {bend }}}{b_{\text {bay }}}=\frac{\Delta u_{\text {tot }}}{b_{\text {bay }}}-\phi_{1}-\frac{\phi_{2}-\phi_{1}}{2}=\frac{\Delta u_{\text {tot }}}{b_{\text {bay }}}-\left(\frac{\phi_{2}}{2}+\frac{\phi_{1}}{2}\right)
$$

\section{EVALUATION OF BUILDING STIFFNESS AT 1-G}

Following the approach of Son \& Cording (2007), Xu et al. (2020) presented results from a series of loading tests to evaluate the structure shear $G A_{s, \text { exp }}$ and bending $E I_{\text {exp }}$ stiffness (computed using Timoshenko beam theory; refer to Xu et al. (2020)) of the frames with raft foundations. Similarly, two 3-point deflection tests were performed on the long frame with 


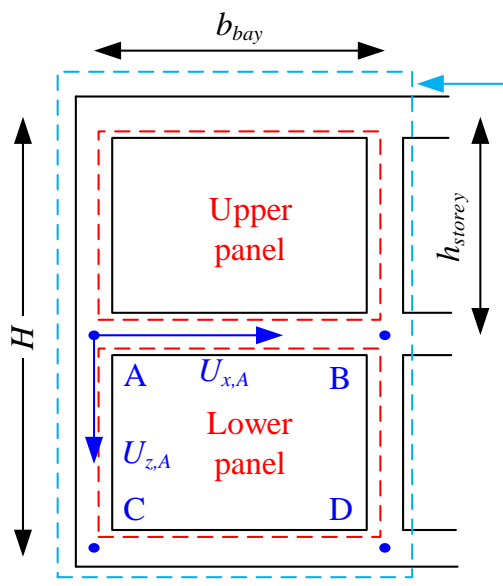

(a) Raft foundation

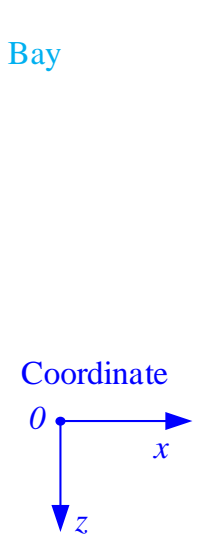

(b) Separate footings

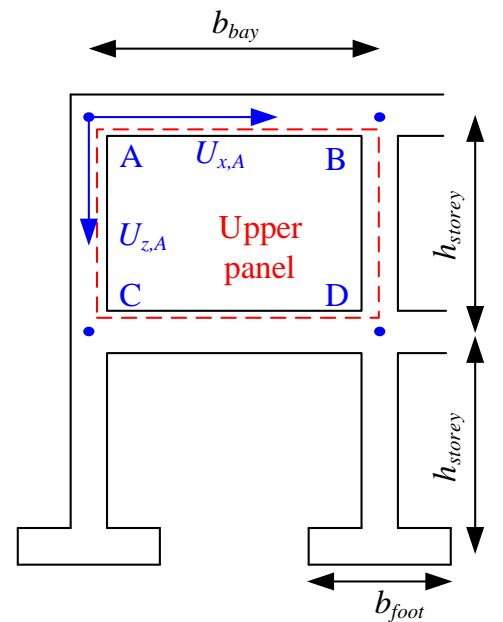

Fig. 3. Definition of building parameters definitions: (a) raft foundation; (b) separate footings.

separate footings with a free span length of either $6 b_{b a y}$ or $4 b_{b a y}$ to quantify the structure total stiffness $K=F / \delta(F$ is the force and $\delta$ is the total deflection) and, again using Timoshenko theory, estimate values of equivalent shear $G A_{s, \exp }$ and bending $E I_{\text {exp }}$ stiffness. In this paper, the term 'structure' refers to both the superstructure (above ground level) and the foundation elements (at the ground level). Figure 4 shows the deformed shapes of the frames in the loading tests, alongside the deformed shapes of the frames on raft foundations from Xu et al. (2020). Table 2 summarises the obtained experimental results of shear $G A_{s, \text { exp }}$ and bending $E I_{\text {exp }}$ stiffness, along with the "pure" equivalent bending stiffness $E I_{E B, e q}$ (obtained using Euler-Bernoulli beam theory) and the values of $\delta_{s} / \delta_{b}$ (the ratio between shear $\delta_{s}$ and bending $\delta_{b}$ deflections from the Timoshenko beam theory when using $G A_{s, \text { exp }}$ and $E I_{\text {exp }}$ ). The data show that all stiffness values of the frame on separate footings are smaller than for the raft foundation, as expected given the removal of the foundation slab. However, in both foundation cases, the deformed shape of the frame is dominated by shear deformation of the panels.
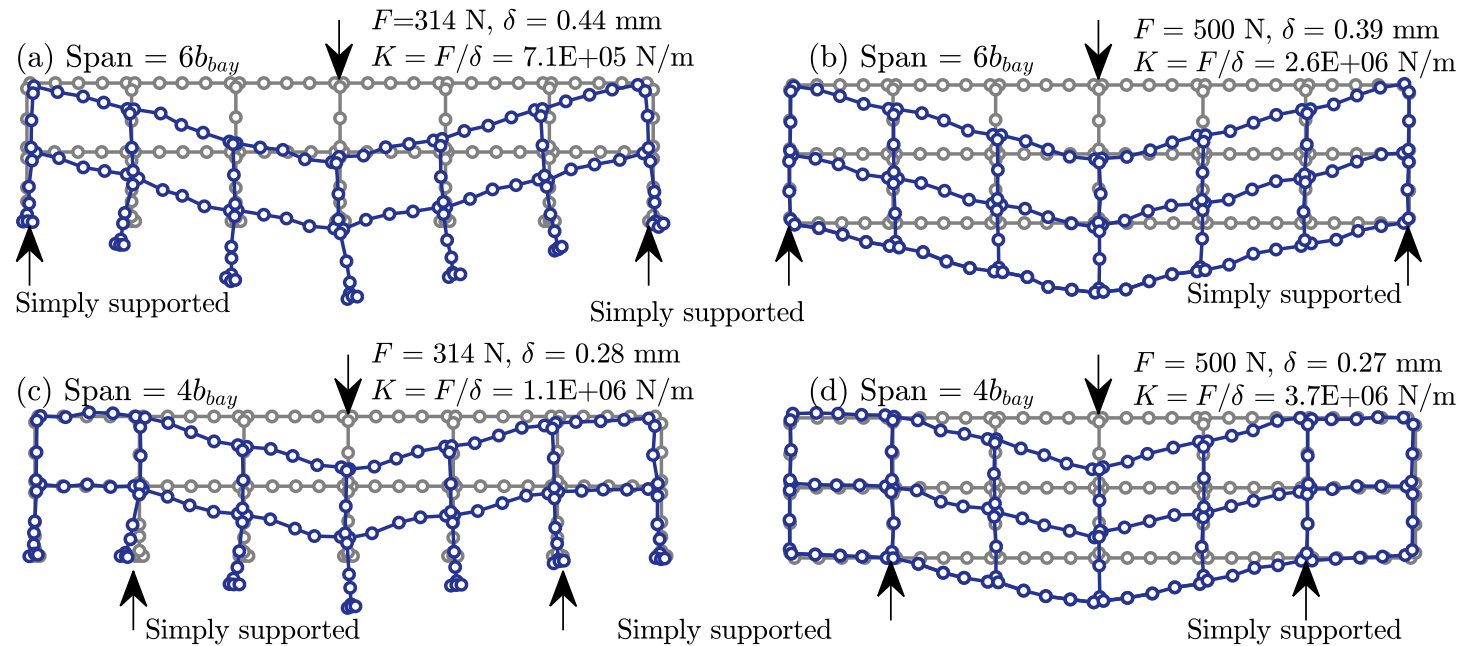

Fig. 4. Frame deformed shapes in the loading tests (scale factor=100): (a) separate footings with a span length of $6 b_{b a y}$; (b) raft with a span length of $6 b_{b a y}$; (c) separate footings with a span length of $4 b_{b a y}$; (d) raft with a span length of $4 b_{b a y}$.

Table 2. Experimental results of bending and shear stiffness of building models (model scale).

\begin{tabular}{ccccc}
\hline Foundation & $E I_{\exp }\left(\mathrm{Nm}^{2}\right)$ & $G A_{s, \exp }(\mathrm{N})$ & $E I_{E B, e q}\left(\mathrm{Nm}^{2}\right)$ & $\delta_{s} / \delta_{b}$ \\
\hline Raft & $5.0 \mathrm{E}+04$ & $1.6 \mathrm{E}+05$ & $2.6 \mathrm{E}+03$ & 18 \\
Separate footings & $1.4 \mathrm{E}+04$ & $9.2 \mathrm{E}+04$ & $1.5 \mathrm{E}+03$ & 8.6 \\
\hline
\end{tabular}

The results of the loading tests highlighted an issue related to the manufacturing process of the model frame buildings, which in particular affected the separate footing model frames. In Figure 4, the central footing (Foot-4) is shown to 
rotate in an anticlockwise direction, whereas ideally no rotation should occur for this footing in the case of a perfectly symmetric scenario; for example, consider the deformed shape obtained from a finite element simulation of the frame loading in Figure S1. This experimental rotation occurred because the footing column is rigidly connected with the rightside beam/slab of the $1^{\text {st }}$ storey (i.e. Bay-4 in Figure 1; this component is a single aluminium angle), whereas the column is welded to the left-side beam/slab of Bay-3. This result indicates that the welding of the connections between slabs and walls did not achieve a perfect fixed-fixed condition (only the top of the slab-column connection is welded) and, consequently, the ground-floor columns did not respond entirely as they should for fixed-fixed connections. This issue mainly affected the horizontal displacements of the separate footings and will be discussed in more detail later. As a result of this issue, the focus of analyses presented in this paper is on settlements of the foundations and distortions of the panels. Note that the left (Foot-1 to 3 ) and right (Foot-5 to 7) three footings moved outwards under loading due to the node rotation caused by the shear deformation; this behaviour is as expected (also observed in the finite element modelling in Figure S1), however each of these footings would also be affected by the issue discussed above.

\section{CENTRIFUGE TEST RESULTS}

\section{Footing loading tests}

The results of the separate footing loading tests, conducted in loose and dense sand to assess the pressure-settlement relationship, are shown in Figure 5, while Table 3 summarises the tested configurations and results. As mentioned earlier, the non-zero initial pressure $q_{0}$ in tests 1 and 2 was used to replicate the effect of the stress beneath the SW and $2 \mathrm{SW}$ separate footings of the model frames (refer to Table 1). Due to the limited capacity of the loading actuator used in test 2 for dense sand, the footing was unloaded prior to reaching a peak load (still providing data for initial and unloading stiffness). Table 3 also provides a summary of the main features of the pressure-displacement curves: the peak resistance of the footing $q_{p}$ in the dense sand tests; the stress in the loose sand tests at which a significant change in the tangent stiffness occurred $q_{c}$; the settlement $S_{c}$ corresponding to $q_{p}$ and $q_{c}$; the initial loading stiffness and the unloading stiffness, taken as a tangent to the 'linear' portion of the initial loading and unloading curves (accepting that the curves are not perfectly linear).

The pressure-settlement curves are highly dependent on soil density, whereas the initial pressure $q_{0}$ and footing position have minor effects. The soil reaction pressure of the loose sand tests (test 1; positions 1 and 2) continuously increased with footing displacement with a distinct change in rate at $q_{c}=460 \mathrm{kPa}$ but with no peak pressure, while the full pressuresettlement curves of the dense sand tests (test 3; positions 1 and 2) presents a peak resistance followed by a reduction at higher settlements (consistent with Vesic (1963); Lau \& Bolton (2011)).

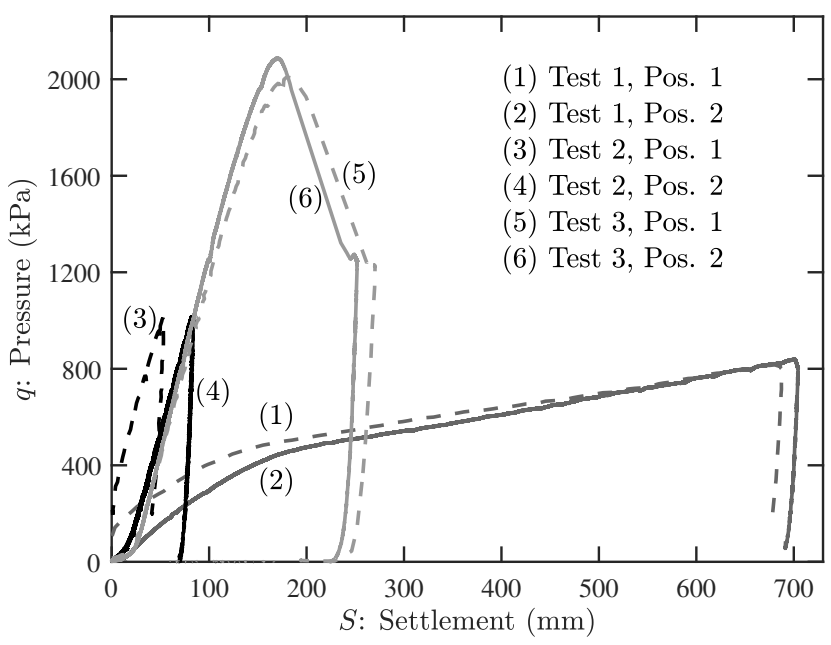

Fig. 5. The response of the footing models to vertical loading (Dimension in prototype)

Interestingly, when the initial pressure is $q_{0}=0$, the settlement $S_{c}$ for both soil densities is within 170-185 mm, corresponding to $21-23 \%$ of the transverse width of the footing. In relation to the tunnel-frame interaction test results presented later (where $q_{0} \neq 0$ ), the effect of applying $q_{0}=101-202 \mathrm{kPa}$ was to decrease the value of $S_{c}$ to $120-150 \mathrm{~mm}$ (estimated for dense soil from test 2 , position 1 by projecting the trend to $q_{p} \approx 2000 \mathrm{kPa}$ ), corresponding to 15 - $18 \%$ of the transverse footing width. Using the values of $q_{p}$ and $q_{c}$ for the dense and loose sand cases, respectively, a safety factor with 
Table 3. Footing loading test results (prototype scale).

\begin{tabular}{|c|c|c|c|c|c|c|c|c|}
\hline No. & Test & $\begin{array}{c}I_{d} \\
(\%)\end{array}$ & Pos. & $\begin{array}{c}q_{0} \\
(\mathrm{kPa})\end{array}$ & $\begin{array}{l}q_{p} \text { or } q_{c} \\
(\mathrm{kPa})\end{array}$ & $\begin{array}{c}S_{c} \\
(\mathrm{~mm})\end{array}$ & $\begin{array}{l}\text { Initial loading stiffness } \\
(\mathrm{kPa} / \mathrm{mm})\end{array}$ & $\begin{array}{l}\text { Unloading stiffness } \\
(\mathrm{kPa} / \mathrm{mm})\end{array}$ \\
\hline (1) & & & 1 & 101 & 460 & 120 & $\begin{array}{l}2.7 \\
\end{array}$ & 64.8 \\
\hline (2) & 1 & 30 & 2 & 0 & 460 & 170 & 2.8 & 78.3 \\
\hline (3) & & 00 & 1 & 202 & - & - & 15.1 & 76.0 \\
\hline (4) & 2 & 90 & 2 & 0 & - & - & 14.8 & 100.1 \\
\hline (5) & 3 & 90 & 1 & 0 & 2010 & 185 & 14.5 & 73.9 \\
\hline (6) & 3 & & 2 & 0 & 2086 & 180 & 16.1 & 111.2 \\
\hline
\end{tabular}

respect to nominal average building pressure (see Table 1) can be computed as $S F \approx 20$ and 10 for the frame on dense soil with standard self-weight $\mathrm{SW}$ and double self-weight $2 \mathrm{SW}$, respectively, while $S F \approx 4.5$ for the $\mathrm{SW}$ frame on loose soil.

\section{Ground deformations}

Figure 6 shows the prototype scale ground movements (horizontal $U_{x}$ and vertical $U_{z}$ ), and strains (engineering shear $\gamma$ and volumetric $\epsilon_{v}$ ) contours for selected tests at a tunnel volume loss of $V_{l, t}=2 \%$. In Figure 6, positive horizontal and vertical displacements are oriented towards the right and downwards, respectively, while positive volumetric strains are contractive.

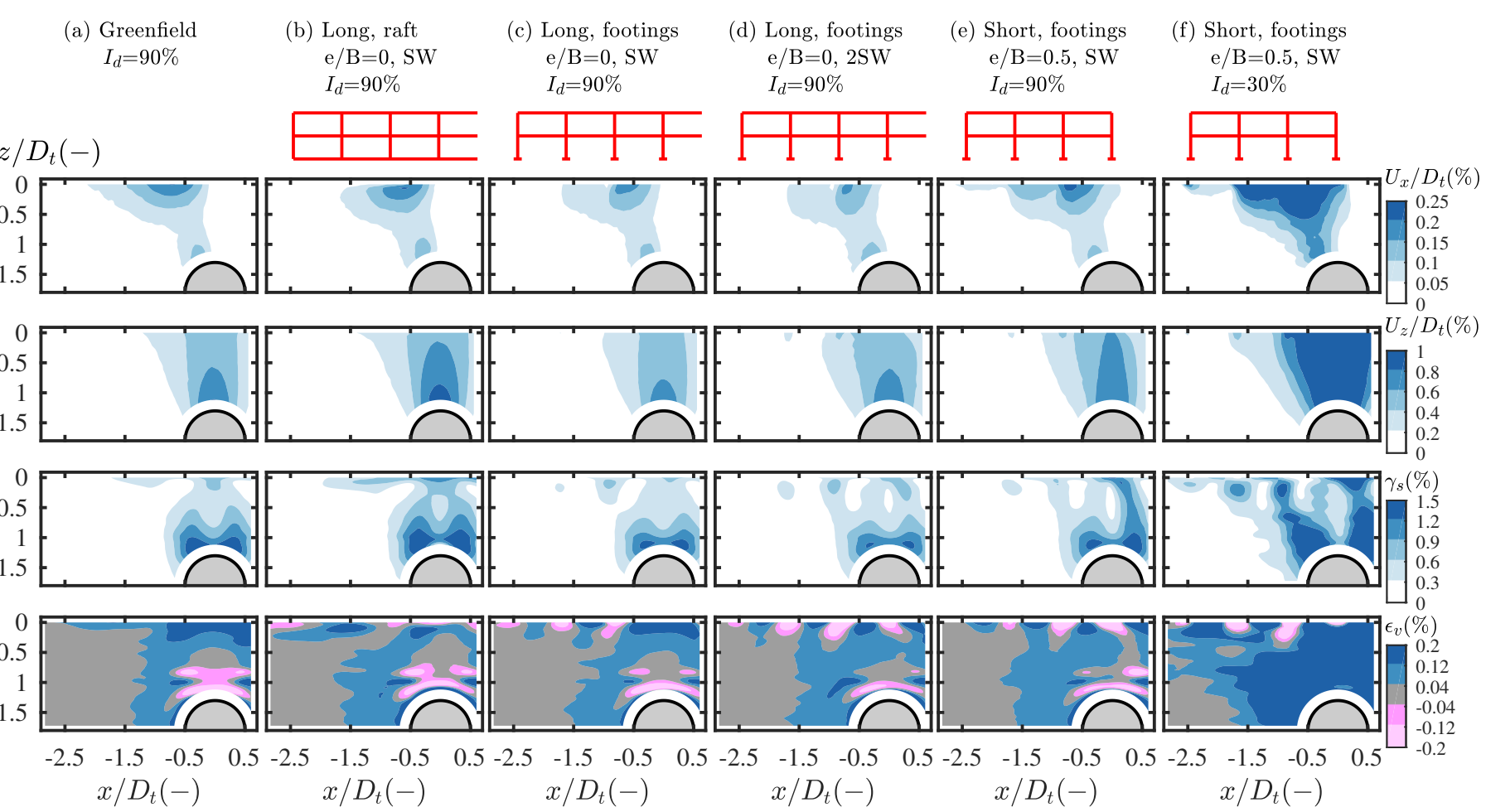

Fig. 6. Soil movements normalised by the tunnel diameter, engineering shear and volumetric strains $\left(\epsilon_{v}<0\right.$ indicates dilation) at $V_{l, t}=2 \%$ (data outside the contour thresholds were set equal to the closest limit value)

From Figure 6(a), the greenfield ground settlement shows a chimney-like pattern due to the low $C / D_{t}$ value (Marshall et al., 2012; Franza et al., 2019), and large shear strains are observed at the tunnel shoulders. Soil directly above the tunnel crown experienced high levels of dilation, whereas the soil experienced intermediate levels of contraction within bands spanning from the tunnel springline to the surface. As discussed by Marshall et al. (2012), the zones of dilation and contraction correspond approximately to the areas of high and low shear strains, respectively. A zone of large contraction is noted centrally above the tunnel and near the surface; this zone is likely caused by the compressive action of the near-surface horizontal displacements on either side of the tunnel.

Firstly the effects, relative to the greenfield case, of the presence of framed buildings with raft foundations is considered. As shown in Figure 6(b), the horizontal displacements of the soil near the surface were largely restricted by the foundation roughness and building pressure towards the external part of the building, whereas the subsurface movements were marginally affected. Interestingly, the soil volumetric strain distribution near the surface was altered by the foundation axial action; this is consistent with the mechanism described by Ritter et al. (2017) that the foundation friction restricted the horizontal ground movements. The restriction of the horizontal soil movements resulted in a thin shear band at the 
soil-foundation interface with a decreased maximum contraction level and some areas of dilation now present. On the other hand, soil settlements increased throughout the ground, accommodated by a slight increase of shear strain at the tunnel shoulders.

For the central frames with standard weight SW on separate footings, as displayed in Figure 6(c), the footings restricted horizontal soil displacements with a distinct change in magnitude at the location of the footings (compared to a more uniform distribution for the raft foundation). The vertical displacement of the soil directly above the tunnel decreased compared with the greenfield case and the raft foundation, accompanied by a decrease of the shear strain. However, localised zones of high shear strain are noted at the footing positions, with dilative response directly beneath the footings and contraction within the soil between footings.

Next, the effect of the building weight is discussed for separate footings. Comparing Figure 6(c) and (d) shows that the increase of building weight slightly increased the settlement, shear and volumetric strains of the soil directly beneath the footings, but had a minor effect on the overall horizontal displacements.

The short eccentric frame with $e / B=0.5$ in Figure 6(e) can be seen as half of the long frame in Figure 6(c). Therefore, data in these figures can be directly compared, with results showing that, because of the freedom to shift, the eccentric short frame in (e) increased the horizontal displacement of the soil near the surface compared with the long central frame in (c). At the same time, the action of the right-most footing (Foot-4) for $e / B=0.5$ resulted in the soil chimney reaching the surface (i.e. larger soil settlements directly above the tunnel up to the surface), and the formation of a large shear band between Foot-4 and the right shoulder area of the tunnel (consistent with Ritter et al. (2017)).

Last, the effect of soil density is evaluated using data in Figure 6 (e) for $I_{d}=90 \%$ and (f) for $I_{d}=30 \%$. The response of the loose soil in the $I_{d}=30 \%$ test is dominated by soil contraction (refer also to Figure 7 ). Consequently, the horizontal and vertical displacements, as well as the shear strain, were significantly increased compared to the $I_{d}=90 \%$ test. Furthermore, the soil around the tunnel for the $I_{d}=30 \%$ test was observed to be in contraction (in contrast to all the $I_{d}=90 \%$ tests where dilation occurred). Interestingly, areas of dilation occurred around the footings for the $I_{d}=30 \%$ test, likely due to the complex rotation/translation response of the footing and the soil shear/volumetric coupling.

\section{Soil volume losses}

In drained soils, because of their contractive/dilative response to shearing, the relationship between soil volume loss $V_{l, s}$ (given by the integration of the soil settlements at a given depth) and tunnel volume loss $V_{l, t}$ (the ground loss at the tunnel boundary) is not 1:1 (as would be the case in undrained soils), which could also have an impact on the tunnel-framed building interaction behaviour. Engineers tasked with designing excavations need to predict/assume reasonable values of soil volume losses given an expected level of tunnel volume loss $V_{l, t}$ for the applied tunnelling operations (Franza et al., 2020).

First, the relationship between surface soil volume loss $V_{l, s}$ and tunnel volume loss $V_{l, t}$ is considered in Figure 7. Overall, soil relative density dominates the $V_{l, s}-V_{l, t}$ relationship. Similar to greenfield tunnelling data (Marshall et al., 2012; Franza et al., 2019), in the tunnel-structure interaction tests, the loose soil exhibits a contractive response, whereas the dense soil transitions from contractive at lower values of $V_{l, t}<1 \%$ towards dilative at higher tunnel volume losses. Regarding the influence of the building, all tests show relatively small effects at $V_{l, t}<1 \%$, whereas minor increases in $V_{l, s}$ can be seen at $V_{l, t}=2-3 \%$. Among the variation of building characteristics (weight, width, foundation type, $e / B$ ), only the building width played a notable role for eccentric structures.

To better quantify the impact of the structure on the ground volumetric behaviour, subsurface values of $V_{l, s}$ are shown in Figure 8 at $V_{l, t}=1$ and $2 \%$ for central structures. Interestingly, the shift of the interaction curves, with respect to the greenfield data, towards greater $V_{l, s}$ values is relatively constant with depth. This shift, due to soil contractive strains, is greater in loose soil. This nearly uniform shift indicates that most of the change in the soil volumetric response (between greenfield and interaction tests) happened at $z / z_{t} \geq 0.7$, i.e. close to the tunnel. Also, note that the behaviour of the soil between the surface and the tunnel crown $\left(z / z_{t}=0-0.7\right)$ is overall contractive in both the loose and dense soils, with $V_{l, s}$ at $z / z_{t}=0$ greater than $V_{l, t}$, hence the dilative response (when present) happened close to the tunnel.

\section{Foundation and ground displacements}

The settlement $U_{z}$ and horizontal displacements $U_{x}$ of the foundations (both raft and separate footings) and underlying soil are presented in this section at a tunnel volume loss $V_{l, t}=2 \%$. Figure 9 focuses on the effect of soil relative density whereas Figure 10 relates to building self-weight. To facilitate data interpretation, selected central structure tests with $e / B=0$ are also directly compared in Figure 11. Note that measured soil settlements directly beneath the foundations were slightly less than those of the foundation in some areas; this inconsistency is mainly due to image analysis errors associated with 


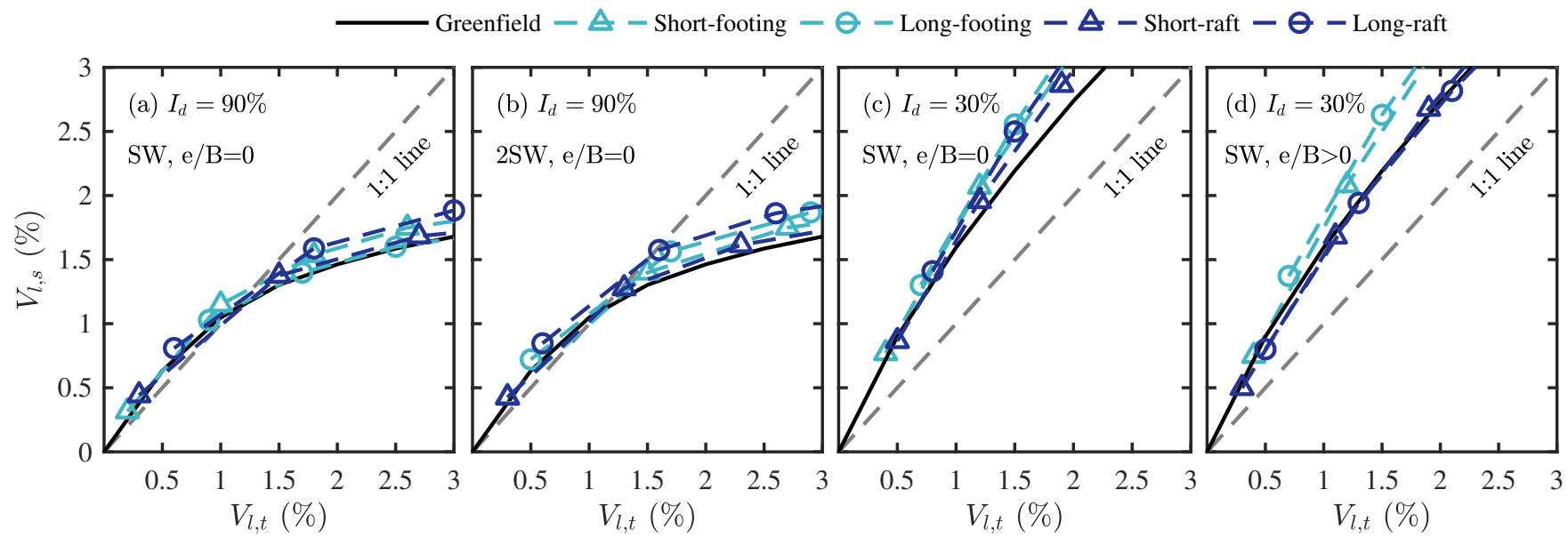

Fig. 7. Soil volume loss against tunnel volume loss: (a) central structures with self-weight $\mathrm{SW}$ in dense soil cases; (b) central structures with double self-weight $2 \mathrm{SW}$ in dense soil cases; (c) central structures with self-weight $\mathrm{SW}$ in loose soil cases; (d) eccentric structures with self-weight SW in loose soil cases.
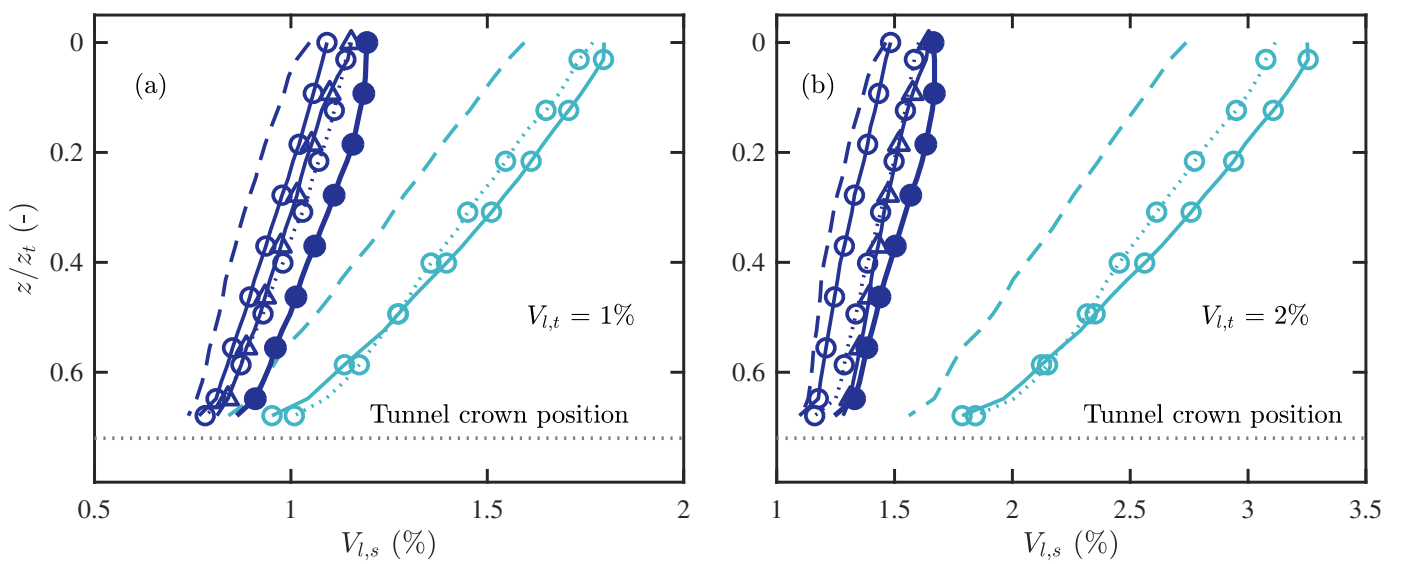

Marker fill

$\Delta \mathrm{SW}$

$\Delta 2 \mathrm{SW}$

Colour type

$\begin{aligned} I_{d} & =30 \% \\ -I_{d} & =90 \%\end{aligned}$

Marker style

$\Delta$ Raft

O Footing

Line style

-..... Short

— - Greenfield

Fig. 8. Soil volume loss with varying depths for $e / B=0$ : (a) $V_{l, t}=\mathbf{1 \%}$; (b) $V_{l, t}=\mathbf{2 \%}$

the small gap between the model frame building and the acrylic wall. This issue also exists in results from other similar centrifuge tests (e.g. Farrell (2010); Ritter (2017)).

The greenfield settlement troughs, which are also provided in Figures 9-11, were characterised by fitting modified Gaussian curves (Vorster et al., 2005) to surface settlement data. As shown in Table 4, the settlement trough width $i$ is similar for both $V_{l, t}=1$ and $2 \%$. However, the maximum settlement $U_{z, \max }$ in the loose soil is considerably larger than that in the dense soil, due to the ratio of $V_{l, s} / V_{l, t}$ presented in Figure 7.

Table 4. Greenfield settlement trough characteristics (prototype scale).

\begin{tabular}{cccccc}
\hline$I_{d}(\%)$ & $V_{l, t}(\%)$ & $V_{l, s}(\%)$ & $U_{z, \max }(\mathrm{mm})$ & $i(\mathrm{~m})$ & trough width parameter $=i / z_{t}(-)$ \\
\hline 30 & 1 & 1.6 & 31.7 & 3.8 & 0.34 \\
90 & 1 & 1.1 & 19.9 & 3.8 & 0.34 \\
30 & 2 & 2.8 & 60.3 & 3.4 & 0.31 \\
90 & 2 & 1.5 & 29.7 & 3.4 & 0.31 \\
\hline
\end{tabular}

To facilitate the description of soil-structure interaction, foundation settlements $U_{z}$ are discussed first. Settlements in Figure 9(a)-(d) shows that the raft foundation frame has a smaller average settlement than the footings. This occurs because the building with a raft foundation is stiffer (see loading test results) and has a lower average soil-foundation contact pressure than the building with separate footings (the raft contact area is around 5 times larger than the footings; see pressures in Table 1). On one hand, for the eccentric configurations with $e / B=0.5$ in Figure $9(\mathrm{~d})$, all footings and the underlying soil settled more than the soil between the footings, particularly for loose soils. This embedment is probably caused by the coupled vertical-horizontal actions of the footings caused by tunnelling, as reported by Elkayam \& Klar (2019). On the other hand, as shown in Figure $9(\mathrm{~b})$ for $e / B=0$, no embedment was measured for the central Foot- 4 above the tunnel, 
which was uplifted by the frame action, while the external footings were embedded by the redistributed building weight (see Figure 2 for footing and bay numbering). Thus, the footing embedment is due to both an increase in vertical loads and/or shearing of the underlying soil. Finally, a gap is observed (where soil settlements are greater than foundation settlements) beneath the middle portion of the long raft in Figure 9(a), as well as beneath the central footing in Figure 9(b) for the loose soil case. In general, centrifuge results in Figure 9(a)-(d) confirm the outcomes of Elkayam \& Klar (2019) that average footing settlements are greater than average greenfield settlements for semi-flexible buildings.
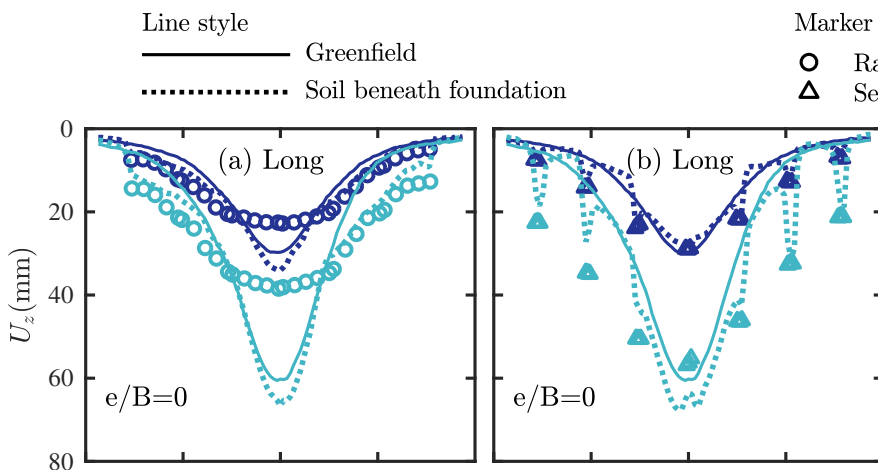

Marker style
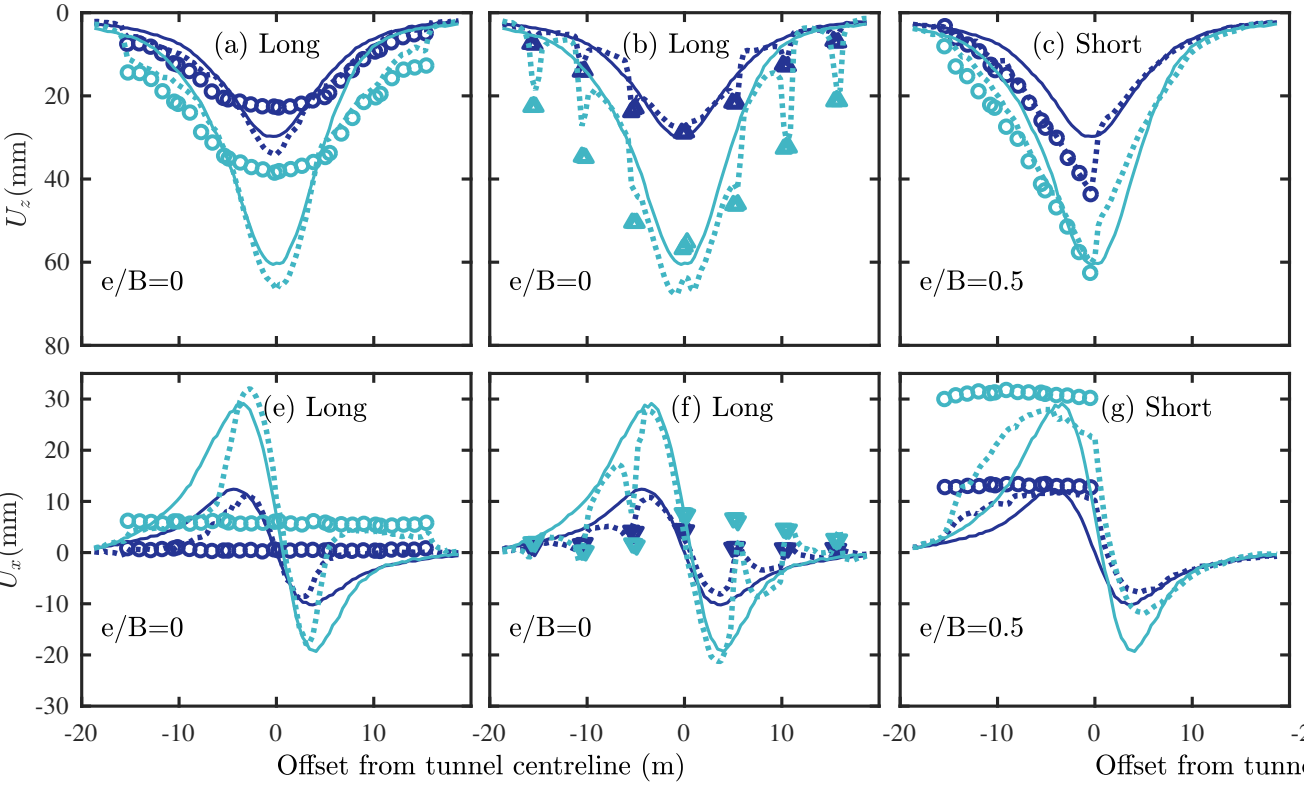

Colour type $I_{d}=90 \%$

$\circ \triangle-I_{d}=30 \%$

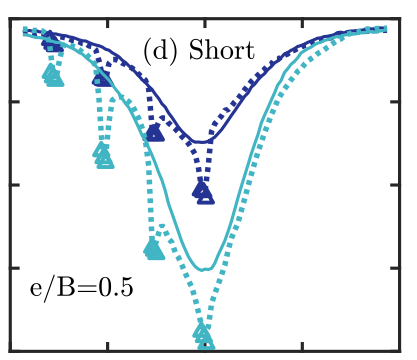

Fig. 9. Foundation and underlying soil displacements for loose and dense soil at $V_{l, t}=2 \%$

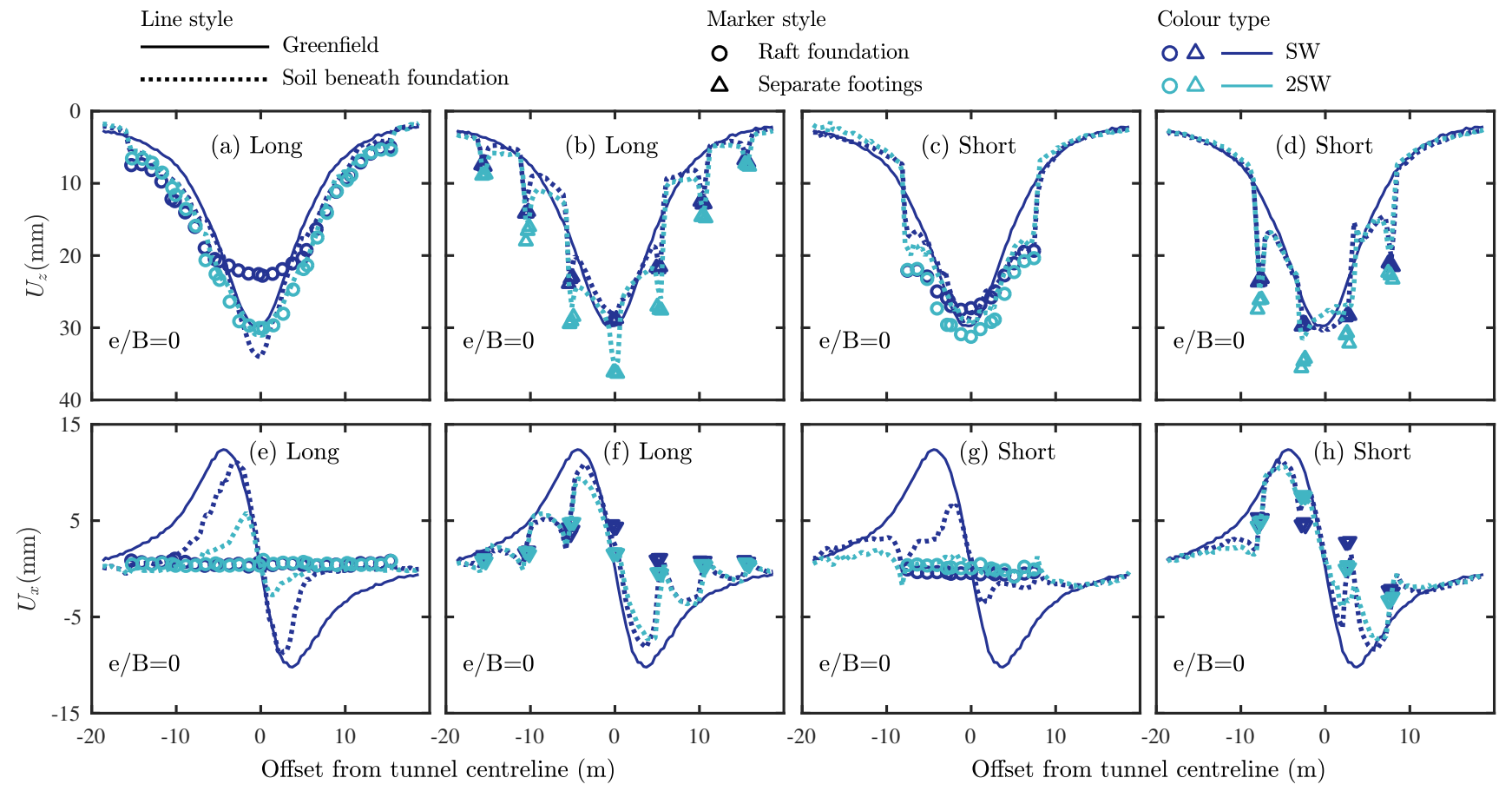

Fig. 10. Foundation and underlying soil displacements with different building weights for dense soil at $V_{l, t}=2 \%$ 


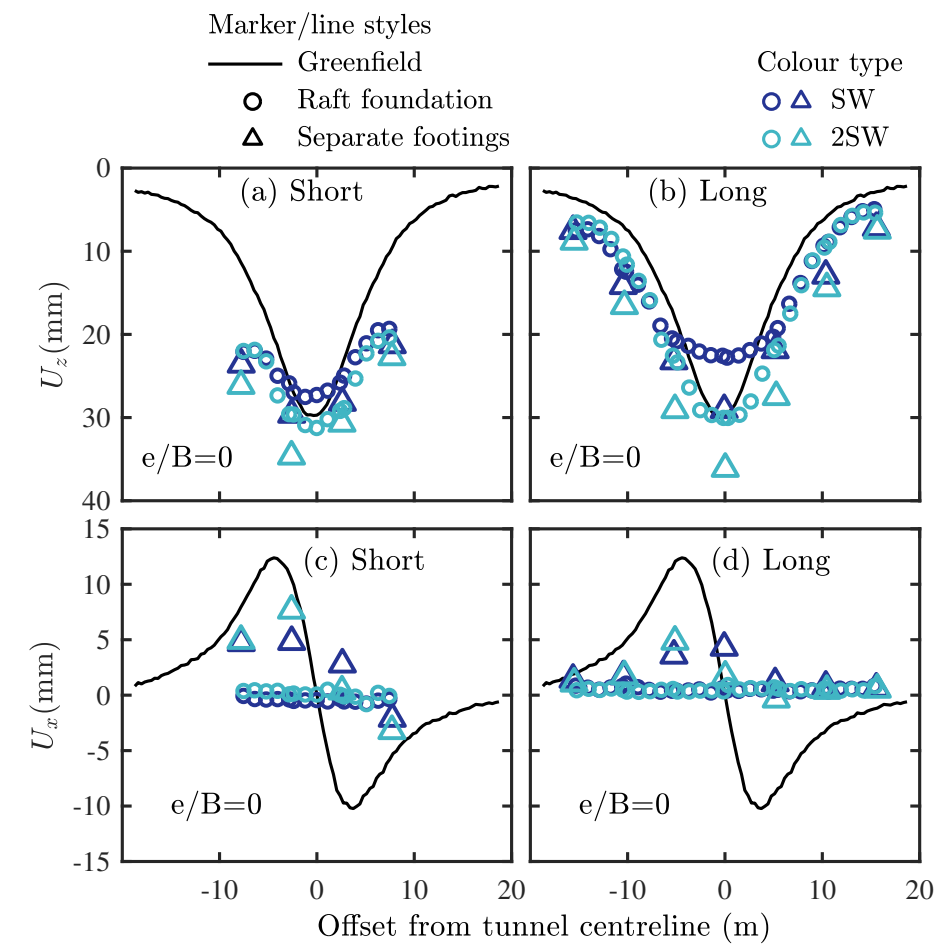

Fig. 11. Foundation displacements for central buildings founded on dense soil at $V_{l, t}=2 \%$.

Regarding horizontal displacements $U_{x}$, Figure $9(\mathrm{e})-(\mathrm{h})$ shows that raft foundations were axially rigid and effectively resisted horizontal ground movements, whereas separate footings underwent non-negligible differential horizontal displacements. Due to uncertainties caused by the model frame manufacturing process mentioned earlier, horizontal displacement data of the footings are only used to indicate general trends caused by a change in test parameter (i.e. those in Table 1). The soil was restricted horizontally where the foundation moved less than the greenfield, whereas movements increased where the foundation shifted more than the greenfield (the trend being continuous for the raft foundations and discontinuous for the separate footings). It is expected that this horizontal action of the foundation, which introduced further shearing within a narrow zone of the soil beneath the foundation (see surface shear band in Figure 6), would degrade the contact shear stiffness of the soil. This aspect could be important for the development of design charts and in evaluating horizontal strain modification factors, similar to Goh \& Mair (2014).

Figure 10 shows the displacement data of the foundations and underlying soil for the central buildings with standard self-weight SW and double weight $2 \mathrm{SW}$ in the dense soil cases. The increase of building weight increased the maximum and differential settlements of the structures on both rafts (accompanied by a decrease of the size of gap in subplots (a) and (c)) and separate footings (associated with an increase of the embedment depth for the footings near the area of maximum soil settlement, for example Foot-3 to 5 in subplot (b) and Foot-2 and 3 in subplot (d)). A heavier building tends to have larger footing differential horizontal displacements (subplots (f) and (h)), especially for the short frame in (h), whereas the horizontal displacements of the raft foundations (subplots (e) and $(\mathrm{g})$ ) are negligible. The raft foundation provided a more significant restriction to the underlying soil horizontal displacement for the increased building weight (subplots (e) and (g)), whereas the effect was marginal for the separate footing cases (subplots $(\mathrm{f})$ and $(\mathrm{h})$ ).

Next, the effect of the building width is considered using data presented in Figure 10. The decrease of building width increased the maximum settlement of the central structures with raft foundations (less true for the 2SW cases) and underlying soil (subplots (a) and (c)), whereas the change of building width had less of an effect on the settlement of the central frame with separate footings (subplots (b) and (d)). For the frames with separate footings, no gap formed regardless of frame width. On the other hand, the short frames with raft foundations embedded into the soil at their edges and showed no gap formation, in contrast to the long frames with raft foundations which showed little edge embedment and a considerable gap for the SW case (but not the 2SW case). For horizontal displacements, the shorter frame on the raft foundation had a more significant effect on restricting the underlying soil (subplots (e) and (g)). This is due to the difference in gap size beneath the foundations for the long and short frame tests, with a wide gap forming beneath the long frame and no gap forming beneath the short frame. 
Finally, the effect of the relative tunnel-building location is discussed, referring to both Figures 9 and 10 . For raft foundations, the increase of eccentricity from $e / B=0$ to 0.5 of the short frame (dark colour in subplots (c) and (g)) decreased the flexural distortion of the building and increased horizontal soil displacements, whereas the central structure restricted them. Similarly, the eccentric short frame on separate footings also displayed lower flexural distortions (subplot (d)). However, the increase of eccentricity of the separate footing buildings changed the deformation mode of the bays at the ground level; for example, differential horizontal displacements of the footings of Bay-2 changed from compression in Figure 10(h) for the central frame to tension in Figure 9(h) for the eccentric frame.

\section{Superstructure deformation parameters}

The shear strain or angular distortion of frame bays/panels provides a more direct estimation of frame deformations than the deflection ratio (Boone, 1996; Xu et al., 2020). Figure 12 presents the variation of maximum shear strain $\gamma$ (from all panels for frames on a raft; from upper panels for frames on footings) against tunnel volume loss $V_{l, t}$ for all presented tests. Results are categorised into four groups based on soil density, building weight, and eccentricity.

General trends for data in Figure 12 relating to raft foundations were reported by Xu et al. (2020). The increase of building weight (subplots (a)-(b)) and the decrease of soil density (subplots (b)-(c)) increased building shear distortions for a given $V_{l, t}$, whereas the increase of building eccentricity (subplots (c)-(d)) decreased building distortions. On the other hand, there is little difference in shear distortion $\gamma$ for separate footings compared to rafts (except for the eccentric long buildings in loose soil, for which the separate footings underwent larger settlements than the greenfield trough), despite the fact that the frames with a raft foundation have a greater structure stiffness than those with footings. This is likely due to the effect of two distinct phenomena affecting the two foundation types. For a given superstructure, the raft foundation contributed to increase the total stiffness of the frame, thereby reducing shear deformations, whereas for the separate footings (which do not contribute to the total frame stiffness), shear deformations were reduced by the effect of tunnelling-induced pressure redistribution beneath the footings, causing higher levels of shear strain within the soil around the footings and reducing the soil-foundation stiffness, resulting in greater structure embedment.

(a) $I_{d}=90 \%, 2 \mathrm{SW}$

$\mathrm{e} / \mathrm{B}=0$, except for short $(\mathrm{e} / \mathrm{B}=0.5)$

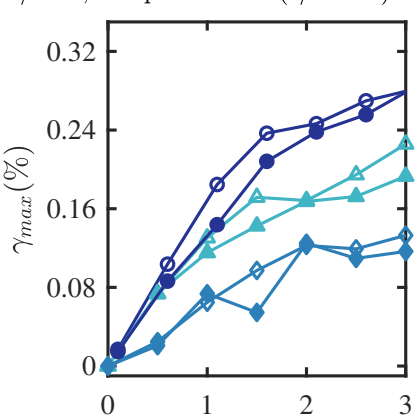

(b) $I_{d}=90 \%, \mathrm{SW}$

$\mathrm{e} / \mathrm{B}=0$, except for short $(\mathrm{e} / \mathrm{B}=0.5)$

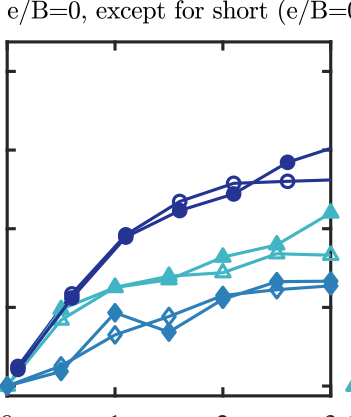

(c) $I_{d}=30 \%, \mathrm{SW}$ $\mathrm{e} / \mathrm{B}=0$

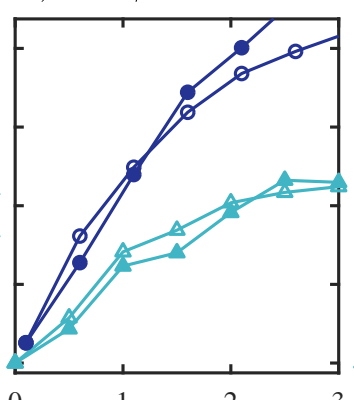

(d) $I_{d}=30 \%, \mathrm{SW}$

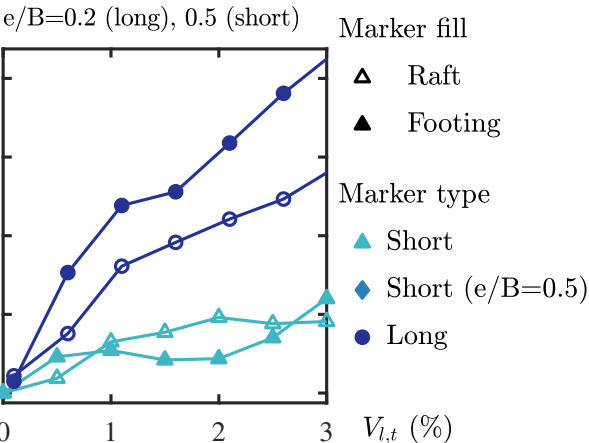

Fig. 12. Maximum shear distortion of the framed buildings with tunnel volume loss $V_{l, t}$

\section{Level of building damage}

Figures 13 and 14 show the deformed shapes of the framed buildings and the ground surface movements for 11 of the centrifuge tests at $V_{l, t}=1$ and $2 \%$, respectively. While in the previous section, the focus was on maximum bay distortions, this section considers the distribution of distortion within panels. To assess the distortion level of panels, indicators are used for the range of shear strain $\gamma$ and the category of damage. Shear strains were inferred from the corner displacements of panels using the approach from Cook (1994), while the tensile strains $\epsilon_{t}=\gamma / 2$ were computed from $\gamma$ using a Mohr's circle of strain under plane-strain conditions while neglecting the horizontal strain of the panels (Son \& Cording, 2005). The category of damage was obtained from the thresholds of Boscardin \& Cording (1989), shown in Table 5. A colour scheme was adopted to denote low (category 0-1); medium (category 2), and high (category 3+) levels of damage (see Table 5).

First, results at $V_{l, t}=1 \%$ in Figure 13 are considered. Overall, most panels of the frames in most tests underwent low levels of damage (negligible or very slight). The frame with separate footings in Figure 13 embedded more into the soil than the frame with raft foundations, while columns underwent bending deflections (e.g. subplots (h) and (i)) due to the horizontal ground movements and the column head rotation at the first storey slab (caused by shear deflections of the frame). As expected, embedment was greater for the loose sand compared to the dense (compare subplot (b) to (e)), and for the 
Table 5. Critical tensile strain and categories of damage (Boscardin \& Cording, 1989).

\begin{tabular}{ccc}
\hline $\begin{array}{c}\text { Category } \\
\text { of damage }\end{array}$ & $\begin{array}{c}\text { Level } \\
\text { of damage }\end{array}$ & $\begin{array}{c}\text { Limiting tensile } \\
\text { strain }(\%)\end{array}$ \\
\hline 0 & Negligible & $0-0.05$ \\
1 & Very slight & $0.05-0.075$ \\
2 & Slight & $0.075-0.15$ \\
3 to 4 & Moderate to severe & $0.15-0.3$ \\
4 to 5 & Severe to very severe & $>0.3$ \\
\hline
\end{tabular}

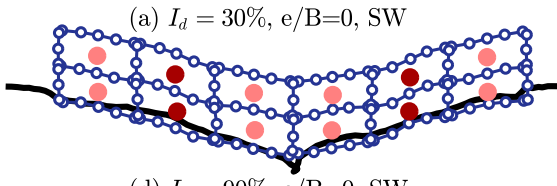

(d) $I_{d}=90 \%, \mathrm{e} / \mathrm{B}=0, \mathrm{SW}$

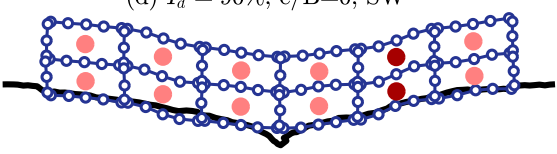

(g) $I_{d}=90 \%, \mathrm{e} / \mathrm{B}=0,2 \mathrm{SW}$

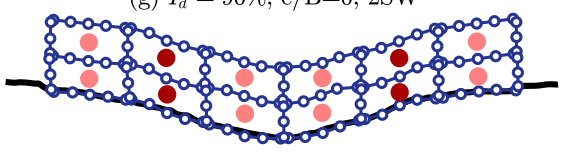

(j) $I_{d}=90 \%, \mathrm{e} / \mathrm{B}=0.5,2 \mathrm{SW}$

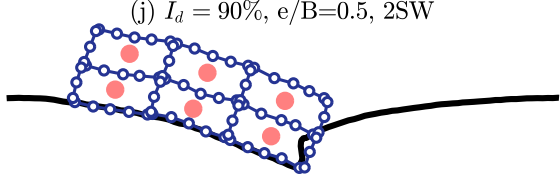

(b) $I_{d}=30 \%, \mathrm{e} / \mathrm{B}=0, \mathrm{SW}$

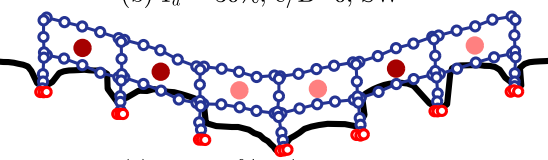

(e) $I_{d}=90 \%, \mathrm{e} / \mathrm{B}=0, \mathrm{SW}$
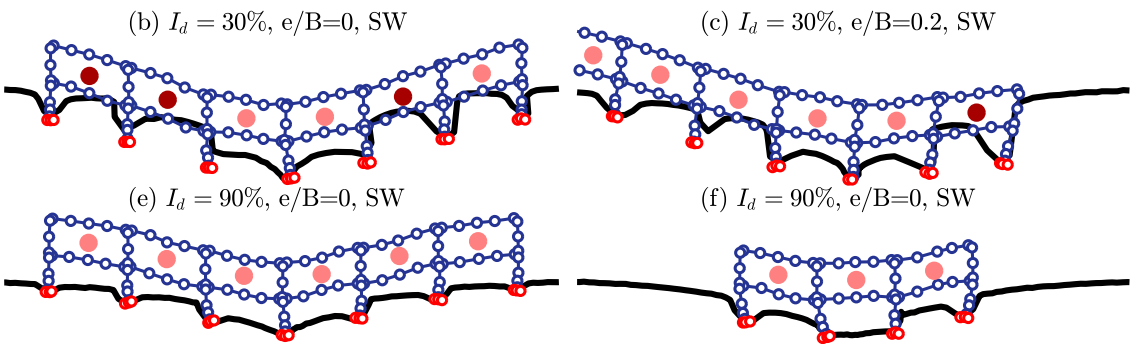

(f) $I_{d}=90 \%, \mathrm{e} / \mathrm{B}=0, \mathrm{SW}$

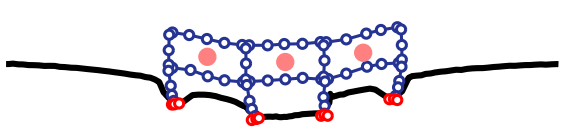

(i) $I_{d}=90 \%, \mathrm{e} / \mathrm{B}=0,2 \mathrm{SW}$

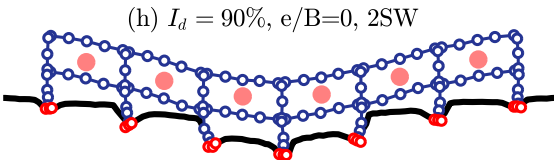

(k) $I_{d}=90 \%, \mathrm{e} / \mathrm{B}=0.5,2 \mathrm{SW}$

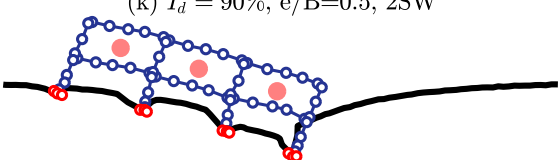

$\begin{array}{rl}\gamma(\%) & \text { Category } \\ 0.3 & 3+ \\ 0.15 & 2 \\ 0 & 0-1\end{array}$

Scale factor: 200

$V_{l, t}=1 \%$

Fig. 13. Framed building deformed shapes and level of damage at $V_{l, t}=1 \%$ (scale factor: 200)

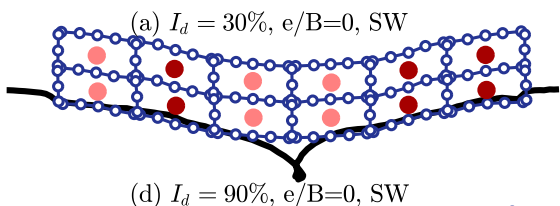

(d) $I_{d}=90 \%, \mathrm{e} / \mathrm{B}=0, \mathrm{SW}$

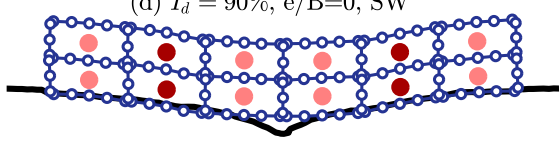

(g) $I_{d}=90 \%, \mathrm{e} / \mathrm{B}=0,2 \mathrm{SW}$
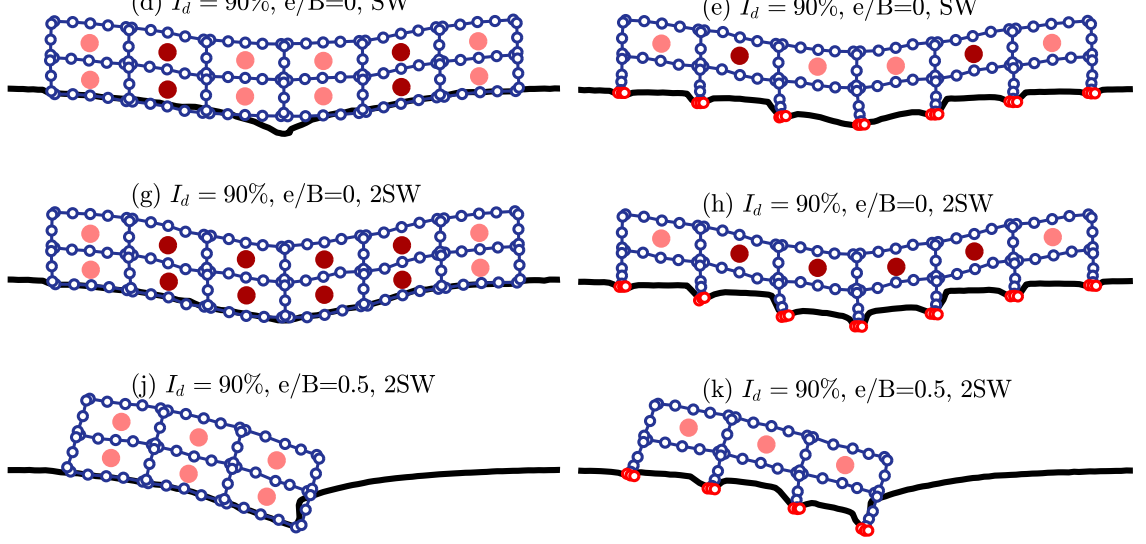

(c) $I_{d}=30 \%, \mathrm{e} / \mathrm{B}=0.2, \mathrm{SW}$

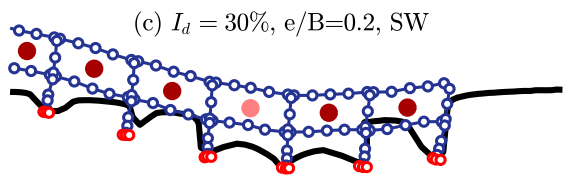

(f) $I_{d}=90 \%, \mathrm{e} / \mathrm{B}=0, \mathrm{SW}$

\$a-a-o-a-o-o-oo:

(i) $I_{d}=90 \%, \mathrm{e} / \mathrm{B}=0,2 \mathrm{SW}$

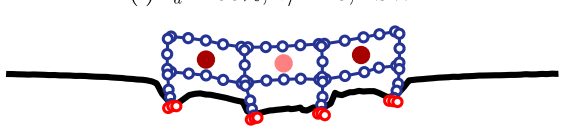

$\begin{array}{rll}\gamma(\%) & \text { Category } & \\ 0.3 & 3+ & \text { Scale factor: } 100 \\ 0.15 & 2 & V_{l, t}=2 \% \\ 0 & 0-1 & \end{array}$

Fig. 14. Framed building deformed shapes and level of damage at $V_{l, t}=2 \%$ (scale factor: 100)

double self-weight 2SW compared to the standard self-weight SW (compare subplot (e) to (h)). Despite the decreased total stiffness of the frame with footings compared to the raft, only the distortion levels of the upper level panels in the loose soil (subplot (b)) are slightly higher than those in the raft (subplot (a)). For the dense soil cases (compare subplots (d)-(e) and $(\mathrm{g})-(\mathrm{h}))$, the frames with rafts have larger deformations in specific panels compared to the footings. This indicates that the structure with separate footings is able to accommodate the differential ground settlement more readily than the raft, through the action of the footing embedment into the soil, thereby reducing the deformation of the structure.

Secondly, data presented in Figure 14 at $V_{l, t}=2 \%$ is discussed. The upper level of panels of long frames with both rafts and footings in dense soil (compare subplots (d) to (e) and (g) to (h)) have the same deformation mode and equivalent 
distributions of maximum damage level. Interestingly, the decrease of soil density (from $I_{d}=90$ to $30 \%$ ) tended to increase the distortion of external panels (panel-1 and 6) of long frames (from low to medium, compare subplot (a) to (d), and (b) to (e), except for panel-1 in (a) to (d)), while the increase of building weight increased the distortion of the internal panels (panel-3 and 4, from low to medium, compare subplot (d) to (g), and (e) to (h)).

Finally, consistent with the findings on raft foundations (Xu et al., 2020), results in Figure 14 confirm that the increase of building eccentricity (comparing (b) to (c), and (i) to (k)), as well as the decrease of the frame width (comparing (e) to (f), and (h) to (i)) decreased the deformation of the frame with separate footings. The short frame experienced lower levels of distortion than the long frame due to its freedom to tilt when subjected to tunnelling (see (g) to (j), and (h) to (k)).

\section{Modification factor against relative soil-building stiffness}

To link excavation-induced framed building angular distortion with relative soil-building stiffness, Xu et al. (2020) used the modification factor of angular distortion, $M^{\beta}$. This modification factor $M^{\beta}=\beta_{\max } / \overline{G S}_{\max }$ is obtained through normalising the maximum angular distortion $\beta_{\max }$, obtained using the equation of Son \& Cording (2005), by the maximum average slope of the portion of the greenfield surface settlement trough spanning a bay width, $\overline{G S}_{\max }=\Delta U_{z, g f, \max } / b_{b a y}$. The trends of $M^{\beta}$ were related to the relative soil-building shear stiffness $\kappa=\left(E_{s} B\right) /\left(G A_{s}^{*}\right)=\left(E_{s} B L\right) /\left(G A_{s}\right)$, where $E_{s}$ is the representative Young's modulus of the soil, $L$ is the length of the building in the longitudinal direction of the tunnel, $G A_{s}^{*}=G A_{s} / L$ is the building shear stiffness per meter run, and $B$ is the building width.

In Figure $15, M^{\beta}$ is plotted against relative soil-building shear stiffness $\kappa$ for $V_{l, t}=1$ and $2 \%$ (numbers beneath markers indicate $V_{l, t}$ ). To highlight the effects of normalised building transverse width and building position relative to the settlement trough on the soil-structure interaction, a colour scheme was adopted to distinguish between values of $e / B$ and the ratio $B / i$, where $i$ is the distance to the inflection point of the greenfield settlement trough.
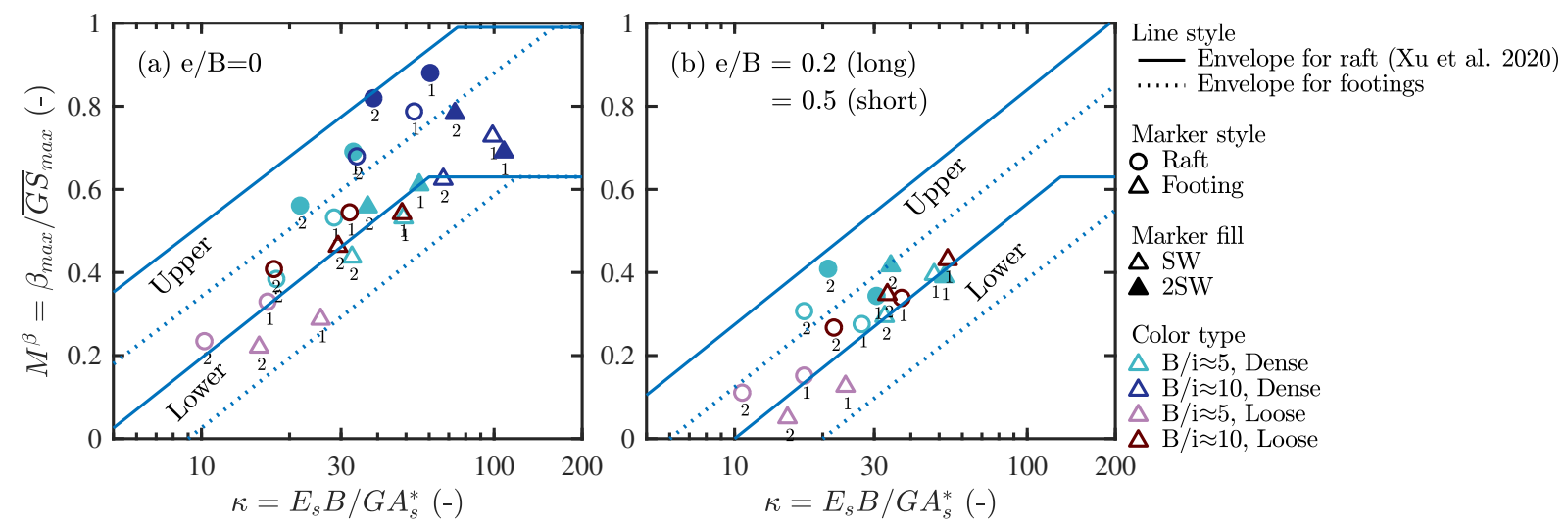

Fig. 15. Modification factors of $\beta$ against relative soil-building shear stiffness at $V_{l, t}=1$ and $2 \%$ ( $V_{l, t}$ indicated by numbers below markers); (a) central structure cases; (b) eccentric structure cases

As can be seen in Figure 15, envelopes for separate footings are suggested and compared with those for raft foundations from Xu et al. (2020). An approximately linear increase of $M^{\beta}$ for separate footings is observed in the semi-log scale with the relative soil-building stiffness. However, for a similar relative stiffness parameter $\kappa$, the frame on separate footings tends to have a smaller $M^{\beta}$ value than the raft foundation. Additionally, this plot confirms that wider $(B / i \approx 10)$ and heavier $(2 \mathrm{SW})$ frames, or structures with a smaller eccentricity $e / B$, tend to have a larger modification factor regardless of the foundation type (as also demonstrated in Figure 12).

\section{CONCLUSIONS}

This paper presented a centrifuge study on soil-framed building interaction, with specific focus on the influence of foundation scheme. Tunnelling-induced displacements of the building and underlying soil were illustrated, and structural and ground deformations were analysed. The following conclusions can be drawn.

- In addition to the building weight and position (e.g. Ritter et al. (2017)), the foundation configuration (i.e. raft or separate footings) significantly affects the ground response and impacts the soil-structure interaction. The foundation type had an impact on both the vertical and horizontal ground displacement fields as well as the shear and volumetric strain distributions. The action of the structure particularly affected the soil close to the foundation, with different 
trends depending on foundation type. Despite this and the differences in strain distributions, only marginal differences in the relationship between tunnel and soil volume loss was observed.

- Buildings with raft and separate footings acted to reduce flexural distortions caused by tunnelling in different ways; separate footings tended to embed into the soil in the areas where settlements were lowest, whereas raft foundations responded by uplifting the portion where settlements were greatest. Because of the embedment, the frame with separate footings settled significantly more than greenfield settlement at the corresponding location, as reported numerically by Elkayam \& Klar (2019).

- In agreement with previous field (Goh \& Mair, 2014) and modelling works (Fu et al., 2018; Franza \& DeJong, 2019), it was confirmed experimentally that tunnelling-induced differential horizontal movements are significant for separate footings, whereas they are negligible for raft foundations.

- For the considered two-storey framed buildings, when only the foundation scheme was changed, the level of shear deformation of the building panels was similar because of two distinct mechanisms: for the raft, shear deformations were reduced because of the higher overall structure stiffness resulting from the raft; for the separate footings, shear deformations were reduced because of higher levels of shear strains in the soil around the footings, reducing the soil-foundation stiffness and causing greater building embedment. The trends highlighted by Xu et al. (2020) for raft foundations were confirmed for separate footings: wider or heavier framed buildings display increased structural shear deformation, whereas building eccentricity reduces distortions for both foundation types.

- The modification factor of the frame angular distortion was linked to the relative soil-building shear stiffness. It was confirmed that the structural stiffness can play an important role in the soil-structure interaction of framed building configurations. With respect to raft foundations, frames on separate footings underwent slightly lower shear modification factors for a given relative stiffness; this is likely due to the fact that footings decreased the foundation footprint compared to rafts, which leads to greater flexibility of the soil-foundation system as well as higher levels of soil shearing (directly beneath the foundation, leading to greater stiffness degradation).

In this paper, the considered scenarios are limited to a tunnel with constant cover-to-diameter ratio constructed in dry sand beneath an elastic framed building. Future works considering the effects of tunnel relative depth, footing buried depth, and nonlinear building behaviour are ongoing.

\section{ACKNOWLEDGEMENTS}

The first author recognises the financial support provided by the China Scholarship Council (CSC) and the University of Nottingham, UK. This project has received funding from the European Union's Horizon 2020 research and innovation programme under the Marie Sklodowska-Curie grant agreement No 793715. 
NOTATION

2SW doubled self-weight of the building

SW

$b_{b a y}$

$b_{\text {foot }}$

$B$

$B_{s}$

$B_{l}$

C

$D_{t}$

$e$

EI

$E I_{E B, e q}$

$E I_{\text {exp }}$

$E_{s}$

F

$G A_{s}$

$G A_{s, e x p}$

$G A_{s}^{*}$

$\overline{G S}_{\max }$

$h_{\text {storey }}$

$H$

$i$

$I_{d}$

$K$

$L$

$M^{\beta}$

$q_{0}$

$q_{p}$

$q_{c}$

$s$

$S$

$S_{c}$

$t$

$U_{i, j}$

$U_{x}$

$U_{z}$

$V_{l, s}$

$V_{l, t}$

$z$

$z_{t}$

$\gamma$

$\gamma_{s}$

$\beta$

$\beta_{\max }$

$\delta$

$\delta_{b}$

$\delta_{s}$

$\Delta_{\text {tot }}$

$\Delta_{\text {bend }}$

$\Delta_{\text {shear }}$

$\Delta_{\text {tilt }}$

$\Delta U_{z, g f, \max }$

$\epsilon_{t}$

$\epsilon_{v}$

$\kappa$

$\phi_{1}$

$\phi_{2}$

$\theta$ self-weight of the building

width of the bay

width of the footing

building width transverse to the tunnel

building width of the short frame

building width of the long frame

cover depth of the tunnel crown

diameter of the tunnel

building eccentricity with respect to the tunnel

bending stiffness

equivalent bending stiffness

experimental bending stiffness

representative Young's modulus of the soil

force

building shear stiffness

experimental building shear stiffness

building shear stiffness per meter run

maximum average slope of a portion of the greenfield surface settlement trough corresponding to $b_{b a y}$

height of the building storey

height of the building

distance to the inflection point of the settlement trough

relatively density of soil

total stiffness

length of the building in the longitudinal direction of the tunnel

modification factor of angular distortion

initial pressure beneath the footing

peak resistance of the footing

stress at which a significant change in the tangent stiffness occurred

slope

footing settlement in loading tests

footing settlement at $q_{p}$ or $q_{c}$

thickness of the building element

corner point displacement; $i$ is the displacement direction, and $j$ is the location of the bay corner

horizontal displacement

vertical displacement

soil volume loss

tunnel volume loss

depth of interest

depth of the tunnel axis

building shear strain

soil engineering shear strain

building angular distortion

maximum building angular distortion

total deflection

bending deflection of the Timoshenko beam

shear deflection of the Timoshenko beam

total building differential settlement

building differential settlement due to bending distortion

building differential settlement due to shear distortion

building differential settlement due to tilt

maximum differential settlement of a portion of greenfield surface settlement trough corresponding to $b_{b a y}$ tensile strain

volumetric strain

relative soil-building stiffness

building/bay left edge tilt

building/bay right edge tilt

tilt 


\section{REFERENCES}

Boldini, D., Losacco, N., Bertolin, S. \& Amorosi, A. (2018). Finite Element modelling of tunnelling-induced displacements on framed structures. Tunnelling and Underground Space Technology 80, No. April, 222-231, doi:10.1016/j.tust.2018.06.019.

Boone, S. J. (1996). Ground-Movement-Related Building Damage. Journal of Geotechnical Engineering 122, 886-896, doi:10.1061/ (ASCE)0733-9410(1996)122:11(886).

Boscardin, M. D. \& Cording, E. J. (1989). Building response to excavation-induced settlement. Journal of Geotechnical Engineering 115, No. 1, 1-21, doi:10.1061/(ASCE)0733-9410(1989)115:1(1).

Comodromos, E. M., Papadopoulou, M. C. \& Konstantinidis, G. K. (2014). Numerical Assessment of Subsidence and Adjacent Building Movements Induced by TBM-EPB Tunneling. Journal of Geotechnical and Geoenvironmental Engineering 140, No. 11, 04014061, doi:10.1061/(ASCE)GT.1943-5606.0001166.

Cook, D. (1994). Studies of settlement and crack damage in old and new facades. In Proc., 3rd Int. Masonry Conference., London, England, vol. 6, pp. 203-211.

Dimmock, P. S. \& Mair, R. J. (2008). Effect of building stiffness on tunnelling-induced ground movement. Tunnelling and Underground Space Technology 23, No. 4, 438-450, doi:10.1016/j.tust.2007.08.001.

Elkayam, I. \& Klar, A. (2019). Nonlinear elasto-plastic formulation for tunneling effects on superstructures. Canadian Geotechnical Journal 56, No. 7, 956-969, doi:10.1139/cgj-2018-0021.

Farrell, R. (2010). Tunnelling in sands and the response of buildings. Ph.D. Thesis, Cambridge University .

Farrell, R., Mair, R., Sciotti, A. \& Pigorini, A. (2014). Building response to tunnelling. Soils and Foundations 54, No. 3, 269-279, doi:10.1016/j.sandf.2014.04.003.

Finno, R. J., Voss, F. T., Rossow, E. \& Blackburn, J. T. (2005). Evaluating Damage Potential in Buildings Affected by Excavations. Journal of Geotechnical and Geoenvironmental Engineering 131, No. 10, 1199-1210, doi:10.1061/(ASCE)1090-0241(2005)131: 10(1199).

Franza, A. \& DeJong, M. J. (2019). Elastoplastic solutions to predict tunnelling-induced load transfer and deformation mechanisms of surface structures. Journal of Geotechnical and Geoenvironmental Engineering 145, No. 4, 04019007, doi:10.1061/(ASCE)GT. 1943-5606.0002021.

Franza, A. \& Marshall, A. M. (2018). Centrifuge Modeling Study of the Response of Piled Structures to Tunneling. Journal of Geotechnical and Geoenvironmental Engineering 144, No. 2, 04017109, doi:10.1061/(ASCE)GT.1943-5606.0001751.

Franza, A., Marshall, A. M. \& Zhou, B. (2019). Greenfield tunnelling in sands: the effects of soil density and relative depth. Géotechnique 69, 297-307, doi:10.1680/jgeot.17.P.091.

Franza, A., Marshall, A. M., Zhou, B., Shirlaw, N., Boone, S., Shirlaw, C. N. \& Boone, S. (2020). Discussion: Greenfield tunnelling in sands : the effects of soil density and relative depth. Géotechnique doi:10.1680/jgeot.19.D.002.

Franzius, J. N., Potts, D. M. \& Burland, J. B. (2006). The response of surface structures to tunnel construction. Proceedings of the ICE - Geotechnical Engineering 159, No. 1, 3-17, doi:10.1680/geng.2006.159.1.3.

Fu, J., Yu, Z., Wang, S. \& Yang, J. (2018). Numerical analysis of framed building response to tunnelling induced ground movements. Engineering Structures 158, 43-66, doi:10.1016/j.engstruct.2017.11.039.

Goh, K. H. \& Mair, R. J. (2014). Response of framed buildings to excavation-induced movements. Soils and Foundations 54, No. 3, 250-268, doi:10.1016/j.sandf.2014.04.002.

Haji, T. K., Marshall, A. M. \& Tizani, W. (2018). A cantilever approach to estimate bending stiffness of buildings affected by tunnelling. Tunnelling and Underground Space Technology 71, 47-61, doi:10.1016/j.tust.2017.08.005.

Laefer, D. F., Ceribasi, S., Long, J. H. \& Cording, E. J. (2009). Predicting RC frame response to excavation-induced settlement. Journal of geotechnical and geoenvironmental engineering 135, No. 11, 1605-1619, doi:10.1061/(ASCE)GT.1943-5606.0000128.

Lanzano, G., Visone, C., Bilotta, E. \& Santucci de Magistris, F. (2016). Experimental Assessment of the Stress Strain Behaviour of Leighton Buzzard Sand for the Calibration of a Constitutive Model. Geotechnical and Geological Engineering 34, No. 4, 991-1012, doi:10.1007/s10706-016-0019-5.

Lau, C. K. \& Bolton, M. D. (2011). The bearing capacity of footings on granular soils. II: Experimental evidence. Geotechnique 61, No. 8, 639-650, doi:10.1680/geot.7.00207.

Mair, R. J., Taylor, R. N. \& Burland, J. B. (1996). Prediction of ground movements and assessment of risk of building damage due to bored tunnelling. In Proceedings of the International Symposium on Geotechnical Aspects of Underground Construction in Soft Ground (Mair, R. J. \& Taylor, R. N., eds.), London, United Kingdom: Balkema, Rotterdam, pp. 713-718.

Marshall, A. M., Farrell, R., Klar, A. \& Mair, R. (2012). Tunnels in sands: the effect of size, depth and volume loss on greenfield displacements. Géotechnique 62, No. 5, 385-399, doi:10.1680/geot.10.P.047.

Ritter, S. (2017). Experiments in tunnel-soil-structure interaction. Ph.D. thesis, Cambridge University .

Ritter, S., Giardina, G., DeJong, M. J. \& Mair, R. J. (2017). Influence of building characteristics on tunnelling-induced ground movements. Géotechnique 67, No. 10, 926-937, doi:10.1680/jgeot.SIP17.P.138.

Ritter, S., Giardina, G., Franza, A., Dejong, M. J. \& Asce, A. M. (2020). Building Deformation Caused by Tunneling : Centrifuge Modeling. Journal of Geotechnical and Geoenvironmental Engineering 146, No. 5, 1-17, doi:10.1061/(ASCE)GT.1943-5606. 0002223. 
Son, M. \& Cording, E. J. (2005). Estimation of Building Damage Due to Excavation-Induced Ground Movements. Journal of Geotechnical and Geoenvironmental Engineering 131, No. 2, 162-177, doi:10.1061/(ASCE)1090-0241(2005)131:2(162).

Son, M. \& Cording, E. J. (2007). Evaluation of Building Stiffness for Building Response Analysis to Excavation-Induced Ground Movements. Journal of Geotechnical and Geoenvironmental Engineering 133, No. 8, 995-1002, doi:10.1061/(ASCE)1090-0241(2007) 133:8(995).

Vesic, A. S. (1963). Bearing Capacity of Deep Foundations in Sand. Highway Research Record 39, 112-153.

Vorster, T. E. B., Klar, A., Soga, K. \& Mair, R. J. (2005). Estimating the Effects of Tunneling on Existing Pipelines. Journal of Geotechnical and Geoenviromental Engineering 131, No. 11, 1399-1410, doi:10.1061/(ASCE)1090-0241(2005)131:11(1399).

White, D., Take, W. \& Bolton, M. (2003). Soil deformation measurement using particle image velocimetry (PIV) and photogrammetry. Géotechnique 53, No. 7, 619-631, doi:10.1680/geot.2003.53.7.619.

Xu, J., Franza, A. \& Marshall, M. A. (2020). The response of framed buildings on raft foundations to tunnelling. Submitted to Journal of Geotechnical and Geoenvironmental Engineering .

Xu, J., Marshall, M. A., Franza, A., Boldini, D., Amorosi, A. \& DeJong, J. M. (2019). The response of framed buildings on raft foundations to tunnelling: a centrifuge and numerical modelling study. In 17th European Conference on Soil Mechanics and Geotechnical Engineering, Reykjavik, Iceland, vol. 1, pp. 1-8.

Zhao, Y. (2008). In situ soil testing for foundation performance prediction. Ph.D. Thesis, Cambridge University .

Zhou, B., Marshall, A. M. \& Yu, H.-S. (2014). Effect of relative density on settlements above tunnels in sands. In 2014 GeoShanghai International Congress: Tunneling and Underground Construction, vol. 242 GSP, Shanghai, China: American Society of Civil Engineers, pp. 96-105, doi:10.1061/9780784413449.010. 
SUPPLEMENTAL DATA
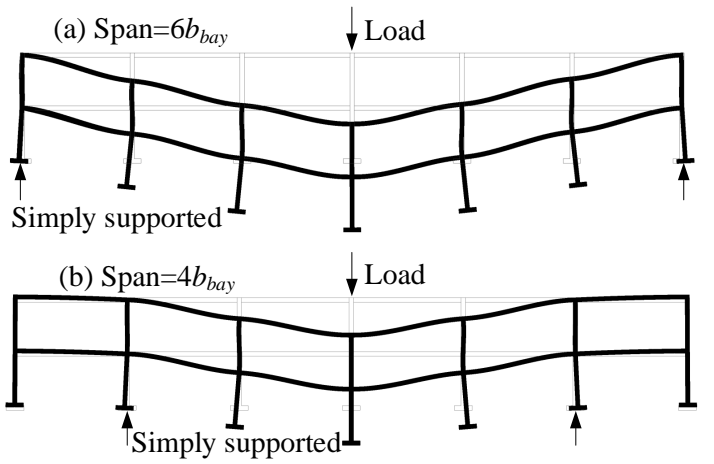

Fig. S1. Deformed shapes of the frames with rigid connections from finite element modelling 